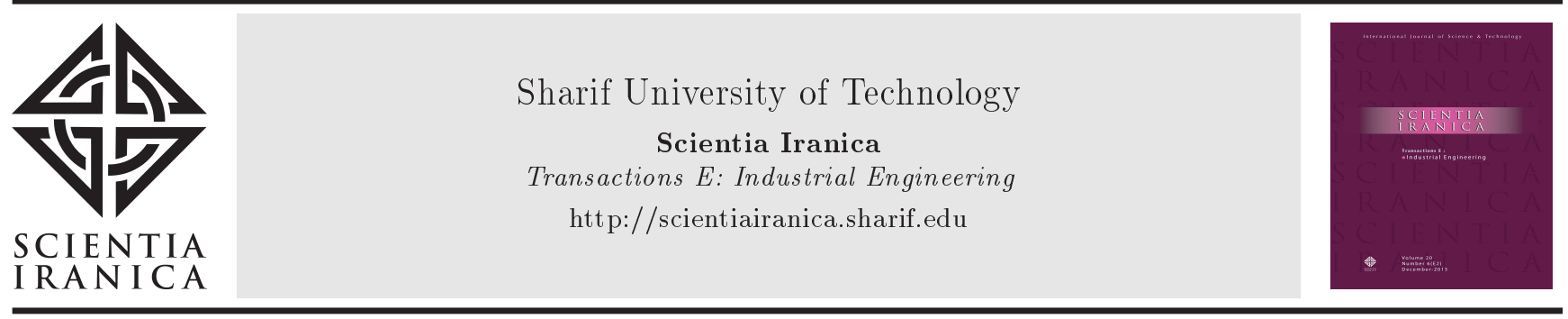

\title{
Integrated and dynamic design of sustainable closed-loop supply chain network considering pricing
}

\author{
A. Nobari* and A. Kheirkhah \\ Department of Industrial Engineering, Faculty of Engineering, Bu-Ali Sina University, Hamedan, Iran.
}

Received 6 April 2016; accepted 2 January 2017

\author{
KEYWORDS \\ Dynamic supply chain \\ network design; \\ Integrated planning; \\ Sustainability; \\ Pricing; \\ Pareto-based \\ multi-objective \\ metaheuristic \\ algorithm.
}

\begin{abstract}
In this paper, a novel multi-objective model for dynamic and integrated network design of sustainable closed-loop supply chain network is proposed, which aims to optimize economic, environmental, and social concerns, simultaneously. In order to have a dynamic design, multiple strategic periods are considered during the planning horizon. Furthermore, different short-term decisions are integrated with long-term decisions related to the network design problem. Two of these short-term decisions determine selling price of products in forward logistics and buying price of used products from customer zones in reverse logistics. Due to the complexity of the proposed multi-objective model, a MultiObjective Imperialist Competitive Algorithm (MOICA) is proposed to solve the model, and the results are compared with a non-dominated sorting genetic algorithm (NSGA-II). Finally, to evaluate the performance of proposed algorithm, several numerical examples are used of which the results indicate the efficiency of the proposed algorithm.
\end{abstract}

(C) 2018 Sharif University of Technology. All rights reserved.

\section{Introduction}

A supply chain can be defined as a systematic network with several echelons cooperating with each other to meet the customers' requirements. Therefore, Supply Chain Management (SCM) is always a main issue [1]. The kind of decisions made in SCM can be categorized into strategic, tactical, and operational levels [2]. The strategic decisions affect the supply chain for a long time, while the tactical and operational decisions have short-lasting effects on the supply chain [3].

One of the most important strategic decisions made in SCM is Supply Chain Network Design (SCND) problem, which attempts to define an efficient in-

\footnotetext{
*. Corresponding author. Tel.: +98 21 r73979418; Fax: +9821 r7385223

E-mail addresses: arashnob@yahoo.com (A. Nobari); amirsamankheirkhah@yahoo.com (A. Kheirkhah)
}

frastructure for a supply chain. Since changing the structure of a supply chain is naturally expensive, many researchers consider the term "network design" as a synonym for strategic planning in supply chain [3-5].

In the recent years, the importance of SCND problem and the interactions among the strategic decisions and tactical performance of the supply chain has made many researchers consider short-term decisions besides strategic SCND problem, which is called Integrated Supply Chain Network Design (Integrated SCND) problem [5]. One of the short-term decisions, which can considerably affect the performance of a supply chain, is pricing. Although many researchers consider price as an static input parameter, it can change dynamically throughout the planning horizon [6]. Hence, it seems more realistic to consider pricing decisions as a tactical decision integrated into the strategic SCND plan.

Nowadays, the new concept of sustainability has entered into different scopes of supply chain problems, such as supply chain network design problem (sustain- 


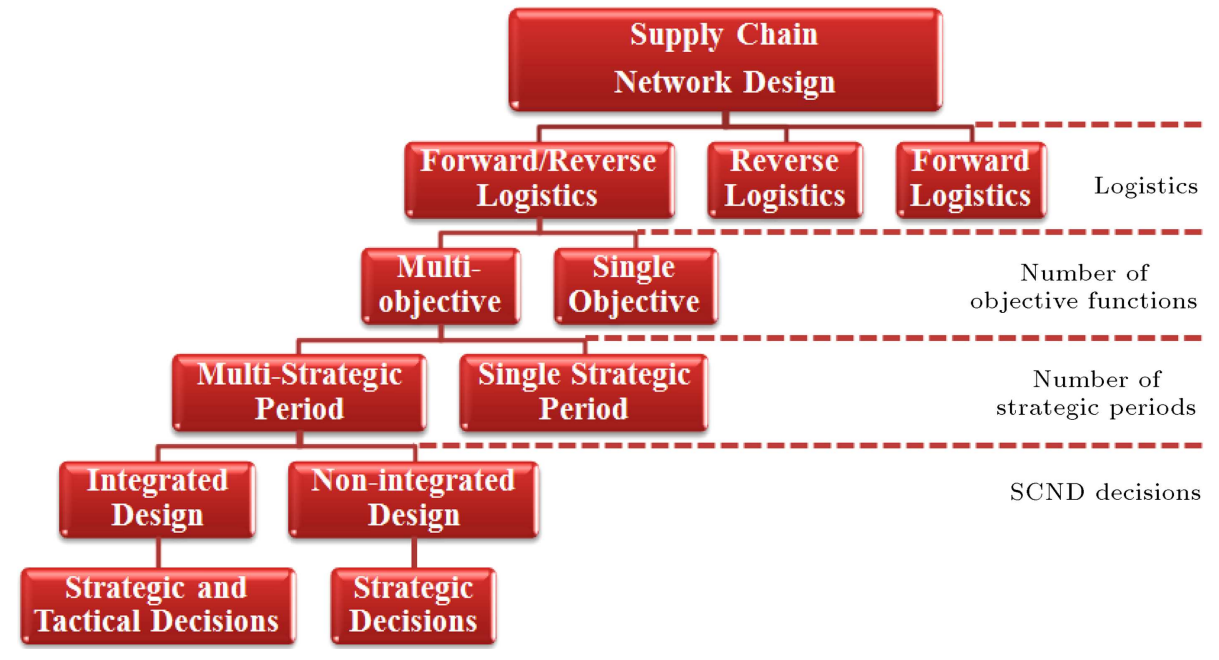

Figure 1. Different aspects of SCND problem.

able SCND). The aim of a sustainable SCND problem is determining the structure of a supply chain so that environmental and social concerns can be responded besides economic ones [7].

From the managerial viewpoint, it is obvious that an efficient management has to consider all aspects of a network design problem. Hence, integrating tactical performance of the supply chain with strategic network design of supply chain is more realistic. Moreover, governmental legislation, environmental concerns, social responsibility, etc. have made managers concentrate on different aspects of their decisions in addition to their economic concerns. Accordingly, this paper presents a novel multi-objective mathematical model for dynamic and integrated network design of a new entrant ClosedLoop Supply Chain (CLSC). The main contributions of this paper are as follow:

- Dynamic design of a sustainable closed-loop supply chain network so that changing the structure of supply chain would be possible with respect to multiple strategic periods;

- Using linear selling price-sensitive demand function for customer zones in forward logistics with respect to selling price as a short-term decision variable;

- Considering buying price decisions in reverse logistics, based on linear buying price-sensitive acquisition function;

- Defining a leveling approach for selling and buying prices in order to have an MILP model;

- Presenting an efficient Pareto-based multi-objective metaheuristic approach for the proposed model.

The rest of this paper is organized as follows: The related literature is reviewed in Section 2. In Section 3, the problem is defined for which a multiobjective MILP model is formulated. Multi-objective
Pareto-based metaheuristic algorithms are described in Section 4. Several numerical examples are analyzed in Section 5. Finally, the conclusion and future research suggestions are given.

\section{Literature review}

Many researches have presented a comprehensive study on logistics network design problem $[2,5]$. Accordingly, the literature on SCND problem can be categorized in different perspectives, as indicated in Figure 1.

\subsection{Categorizing based on supply chain logistics}

The first group concentrates on the forward logistics [816]. The main goal of these papers is to design the network of facilities to operate in forward logistics.

The second group focuses only on designing the structure of reverse logistics facilities [17-20]. In these researches, only backward activities are considered.

The last group considers both forward and reverse logistics in SCND problem [21-30]. Some of these researches investigate designing of supply chains that attempt to turn back the used products to their forward logistics, called closed-loop supply chain [21-24,26-30].

In the recent years, a considerable number of researches have discussed reverse and closed-loop supply chain network design problems [31].

\subsection{Categorizing based on the number of objective functions}

The first group studies the SCND problem considering a single metric. More than $90 \%$ of the researches before 2009 considered single-objective function in SCND problem [2].

The other group considers several objective functions in the SCND problem, simultaneously [5]. One of the new concepts added to the literature on multi-objective supply chain models is sustainability 
$($ see $[32,33])$. Some researchers have surveyed sustainable SCND problem during recent years [34-35].

\subsection{Categorizing based on the number of strategic periods}

The first group considers a single strategic period in SCND problem in which the structure of supply chain network cannot be changed [6].

The second group studies SCND problem during multiple strategic periods in which the structure of supply chain can be changed dynamically $[13,16,24,26,29]$. The number of these researches is considerably less than that for the single-period ones [36].

\subsection{Categorizing based on the decisions made in $S C N D$}

The first group concentrates only on strategic decisions, which include most of the first researches on SCND problem [2].

The second group considers short-term decisions in strategic SCND problem. A comprehensive study was presented by Shen [37].
There are only a few researches in the literature on SCND problem which have considered multiple strategic and multiple tactical periods, simultaneously $[6,12,38]$.

Accordingly, it can be observed that a small part of researches considers dynamic supply chain network design problem. This paper attempts to propose a comprehensive model for a dynamic sustainable supply chain network design problem, which integrates pricing decisions in addition to several common tactical decisions into the strategic SCND problem. The characteristics of the current paper with respect to relevant works are indicated in Table 1.

\section{Problem definition}

In this paper, dynamic design of a new entrant closedloop supply chain network is considered. The configuration of this CLSC is shown in Figure 2. In the forward logistics, the plants obtain the required raw materials from suppliers and produce products. The final products should be delivered to the customer

Table 1. The literature on SCND.

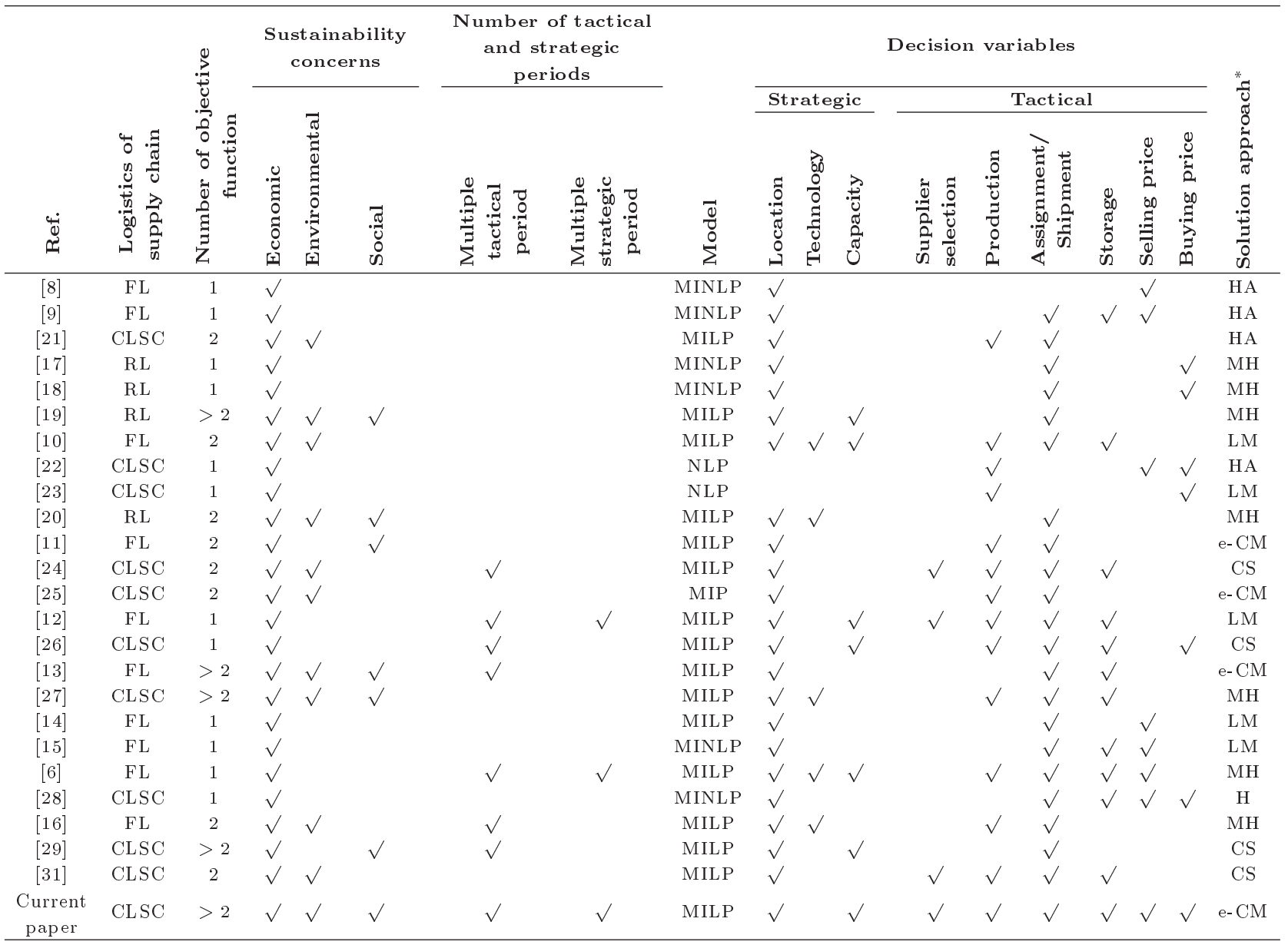

*HA: Heuristic Approach; MH: Meta-Heuristic Approach; LM: Lagrangian Method; CS: Commercial Solver; e-CM: $\varepsilon$-Constraint Method. 


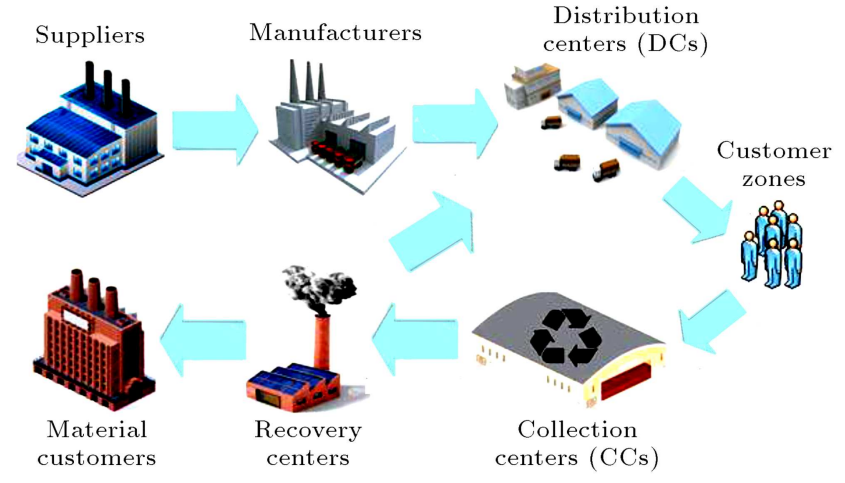

Figure 2. Configuration of closed-loop supply chain.

zones via DCs. In the reverse logistics, collection centers $(\mathrm{CCs})$ collect a portion of the used products from customer zones and deliver them to Recovery Centers (RCs), which inspect the returned products and separate them into repairable and decomposed groups. I9t supposes that the repaired products, which are reusable, will be delivered to DCs directly and the decomposed products will be sold to material customer zones.

It is supposed that in addition to the mentioned entrant supply chain, there is an existing supply chain, which sells the same products and seizes a part of overall demand in each customer zone, and the new entrant closed-loop supply chain can achieve the remaining. Hence, both new entrant and existing supply chains have their own market share and there is no competition among them.

It is assumed that the planning horizon consists of multiple strategic periods so that each strategic period includes multiple tactical periods, as shown in Figure 3.

It is also assumed that there is a budget assigned to each strategic period, which can be spent partially and the unspent will be invested in another project with a predefined interest rate.

The aim of this SCND problem is defining the proper structure for a sustainable closed-loop supply chain so that the total profit of supply chain will be maximized, the amount of greenhouse gases emission related to supply chain activities will be minimized, and the job opportunities created by supply chain will be maximized, simultaneously.
The other assumptions of the proposed model are as follow:

- The set of potential locations for facilities of different echelons is determined;

- The opened facilities in each strategic period cannot be closed during the next strategic periods;

- The set of potential capacity options for each manufacturer is determined;

- The maximum capacity of each facility is known;

- The demand function of each customer zone is a linear selling price-dependent function;

- The accusation function of used products in each customer zone is a linear incentive buying pricedependent function;

- Shortages can occur in form of lost sales;

- The delivered recovered products in each recovery center will be received by DCs after one tactical period;

- All parameters considered in closed-loop supply chains are deterministic.

\subsection{Notations}

Sets

$S \quad$ Set of suppliers $(s \in S)$

$M \quad$ Set of potential manufacturers $(m \in M)$

$D \quad$ Set of potential distribution centers $(d \in D)$

$K \quad$ Set of potential customer zones $(k \in K)$

C Set of potential collection centers $(c \in C)$

$R \quad$ Set of potential recovery centers $(r \in R)$

$C^{\prime} \quad$ Set of material customers $\left(c^{\prime} \in C^{\prime}\right)$

$P \quad$ Set of products $(p \in P)$

$P^{\prime} \quad$ Set of raw materials $\left(p^{\prime} \in P^{\prime}\right)$

$L \quad$ Set of selling price levels $(l \in L)$

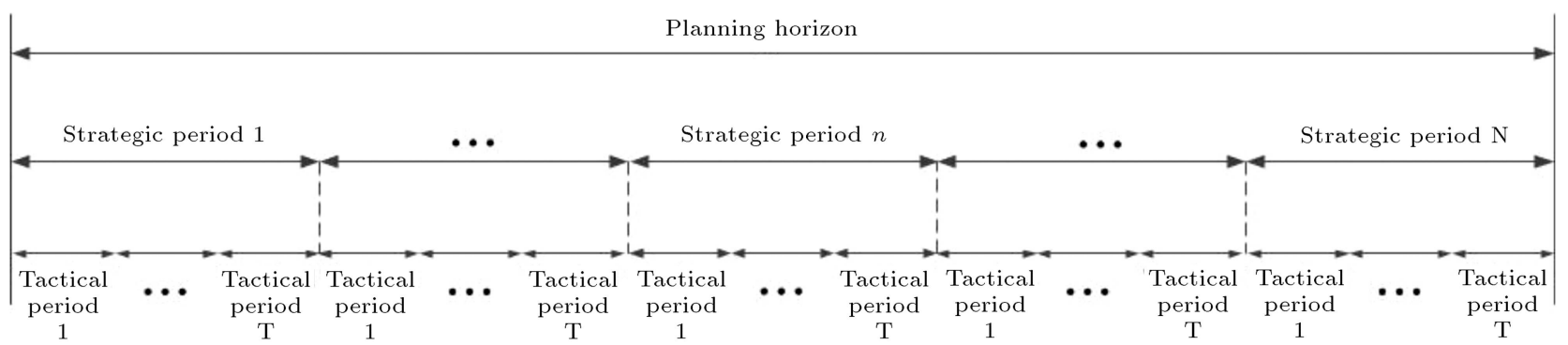

Figure 3. Relationship between strategic and tactical periods. 
$L^{\prime} \quad$ Set of return price levels $\left(l^{\prime} \in L^{\prime}\right)$

$O \quad$ Set of production capacity options $(o \in O)$

$N \quad$ Set of strategic periods $(n \in N) . n=0$ is a period before planning horizon.

$T \quad$ Set of tactical periods $(t \in T)$

\section{Parameters}

\section{Economic parameters}

$F O_{i}^{n} \quad$ Fixed cost charged in strategic period $n-1$ for opening facility in strategic period $n$,

$F A_{m, o}^{n} \quad$ Fixed cost of manufacturer $m$ charged in strategic period $n-1$ for adding production capacity option $o$ in strategic period $n$,

$F C C_{m, o}^{n} \quad$ Fixed cost of manufacturer $m$ to operate under capacity option $o$ in strategic period $n$,

$F O C_{i} \quad$ Fixed operating cost of facility $i$,

$B C_{s, p^{\prime}} \quad$ Variable cost of one unit of product $p^{\prime}$ from supplier $s$,

$P C_{m, p} \quad$ Variable cost of producing one unit of product $p$ at manufacturer $m$,

$H C_{d, p} \quad$ Variable cost of holding one unit of product $p$ at distribution center $d$,

$S C_{k, p} \quad$ Variable shortage cost of one unit of product $p$ at customer zone $k$,

$I C_{r, p} \quad$ Variable cost of inspecting one unit of product $p$ at recovery center $r$,

$R C_{r, p} \quad$ Variable cost of recovering one unit of product $p$ at recovery center $r$,

$T C_{s, m, p^{\prime}} \quad$ Variable cost of transporting one unit of raw material $p^{\prime}$ between supplier $s$ and manufacturer $m$,

$T C_{i, j, p} \quad$ Variable cost of transporting one unit of product $p$ between facilities $i$ and $j$,

$S V_{c^{\prime}, p} \quad$ Variable revenue of selling one unit of unrecovered product $p$ to material customer $c^{\prime}$,

\section{Emission parameters}

$E F_{i} \quad$ GHG emission coefficient to establish facility $i$,

$E P_{m, p} \quad$ GHG emission coefficient to produce one unit of product $p$ at manufacturer $m$,

$E S_{d, p} \quad$ GHG emission coefficient to store one unit of product $p$ at distribution center $d$,
$E I_{r, p} \quad$ GHG emission coefficient to inspect one unit of product $p$ at recovery center $r$,

$E R_{r, p} \quad$ GHG emission coefficient to recover one unit of product $p$ at recovery center $r$

$E T_{s, m, p^{\prime}} \quad$ GHG emission coefficient to transport one unit of raw material $l^{\prime}$ from supplier $s$ to manufacturer $m$,

$E t_{i, j, p} \quad$ GHG emission to transport one unit of product $p$ from facility $i$ to facility $j$,

\section{Job creation parameters}

$J_{i} \quad$ Number of job opportunities created due to opening facility $i$,

\section{Other parameters}

$\operatorname{Exp}_{m, o} \quad$ Capacity expansion of capacity option $o$ at manufacturer $m$,

$\mathrm{Cap}_{m}^{\max } \quad$ Maximum installable production capacity of manufacturer $m$,

Cap $p_{d}^{\max } \quad$ Maximum storage capacity of distribution center $d$,

$\mathrm{Cap}_{c}^{\max } \quad$ Maximum collecting capacity of collection center $c$,

$\mathrm{Cap}_{r}^{\max } \quad$ Maximum recovery capacity of recovery center $r$,

$U_{m} \quad$ Utilization rate of manufacturer $m$,

$\rho_{p^{\prime} p} \quad$ Quantity of required raw material $p^{\prime}$ to produce one unit of product $p$,

$U r_{m, p} \quad$ Usage rate of production capacity for manufacturer $m$ to produce one unit of product $p$,

$U r_{p} \quad$ Usage rate of storage capacity for each distribution center to store one unit of product $p$,

$A_{m, d} \quad$ Number of deliveries from manufacturer $m$ to distribution center $d$,

$A_{r, d} \quad$ Number of deliveries from recovery center $r$ to distribution center $d$,

$\alpha_{k, p} \quad$ Return rate of used product $p$, collected freely and without buying from customer zone $k$,

$\beta_{k, p} \quad$ Elasticity coefficient of selling price in demand function of customer zone $k$ for product $p$,

$\beta_{k, p}^{r} \quad$ Elasticity coefficient of buying price in acquisition function of customer zone $k$ for product $p$,

$\gamma_{p}$

Recoverable fraction of returned product $p$, 


\begin{abstract}
$P r_{k, p, l}^{n, t} \quad$ Selling price of product $p$ to customer zone $k$ at price level $l$ in tactical period $t$ of strategic period $n$,

$\omega \quad$ Rate of existing supply chain's market share, which is not achievable by entrant supply chain,

$\operatorname{Demand}_{k, p}^{n, t} \quad$ Potential demand of customer zone $k$ for product $p$ in tactical period $t$ of strategic period $n$,

MaxDem $\operatorname{De}_{k, p}^{n, t}$ Maximum achievable market share of customer zone $k$ for product $p$ in tactical period $t$ of strategic period $n$,

$\operatorname{Dem}_{k, p}^{n, t} \quad$ Demand of customer zone $k$, related to entrant supply chain, for product $p$ in tactical period $t$ of strategic period $n$,

$\operatorname{Dem}_{k, p, l}^{n, t}$

Demand of customer zone $k$, related to entrant supply chain, for product $p$ in tactical period $t$ of strategic period $n$ based on selling price level $l$,

$I P r_{k, p, l^{\prime}}^{n, t} \quad$ Buying price of product $p$ in customer zone $k$ at price level $l^{\prime}$ in tactical period $t$ of strategic period $n$,

$\operatorname{Ret}_{k, p, l^{\prime}}^{n, t} \quad$ The amount of returned product $p$ from customer zone $k$ in tactical period $t$ of strategic period $n$ based on incentive price level $l^{\prime}$,

$B_{n} \quad$ Budget assigned to strategic period $n$,

$I R_{n} \quad$ Interest rate of investing in foreign project in strategic period $n$,
\end{abstract}

\section{Decision variables}

\section{Binary variables}

$O M_{m}^{n} \quad 1$ if manufacturer $m$ is open during strategic period $n$,

$O D_{d}^{n} \quad 1$ if distribution center $d$ is open during strategic period $n$,

$O C_{c}^{n} \quad 1$ if collection center $c$ is open during strategic period $n$,

$O R_{r}^{n} \quad 1$ if recovery center $r$ is open during strategic period $n$,

$O_{m, o}^{n} \quad 1$ if capacity option $o$ is installed at manufacturer $m$ in strategic period $n$,

$\varepsilon_{k, p, l}^{n, t} \quad 1$ if selling price level $l$ is used for selling product $m$ to customer zone $k$ in tactical period $t$ of strategic period $n$,

$\varphi_{k, p, l}^{n, t} \quad 1$ if buying price level $l^{\prime}$ is used for buying additional used product $m$ from customer zone $k$ in tactical period $t$ of strategic period $n$,

\section{Continuous variables}

$Q_{m, p}^{n, t}$

Quantity of product $p$ produced by manufacturer $m$ in tactical period $t$ of strategic period $n$,

$H_{d, p}^{n, t}$

Amount of product $p$ held by distribution center $d$ in tactical period $t$ of strategic period $n$,

$f_{s, m, p^{\prime}}^{n, t}$

$f_{i, j, p}^{n, t}$

Amount of raw material $p^{\prime}$ shipped from supplier $s$ to manufacturer $m$ in tactical period $t$ of strategic period $n$,

Amount of product $p$ shipped from facility $i$ to facility $j$ in tactical period $t$ of strategic period $n$,

$S_{k, p, l}^{n, t}$

Shortage of product $p$ based on price level $l$ in customer zone $k$ in tactical period $t$ of strategic period $n$,

$U B_{n} \quad$ Unspent budget in strategic period $n$,

$S B_{n} \quad$ Spent budget in strategic period $n$ to extend the network of supply chain,

Cost $_{\text {Fixed }}$ Total operational fixed cost of supply chain through planning horizon,

Cost $_{V a r}$ Total operational variable cost of supply chain through planning horizon,

Cost $_{\text {total }}$ Total cost of supply chain through planning horizon,

Income $_{\text {total }}$ Total income of supply chain through planning horizon,

\subsection{Price-dependent demand functions}

There are different price-sensitive response functions, which have been used in the literature [39]. In this paper, a linear case of price-response functions, which are usually suitable for the cases that small changes of selling price lead to considerable decrease in customers' demand and the willingness to pay is uniformly distributed, is used [6]. Based on this linear relationship, which is shown in Figure 4, the demand function of customer zones can be formulated as Eq. (1):

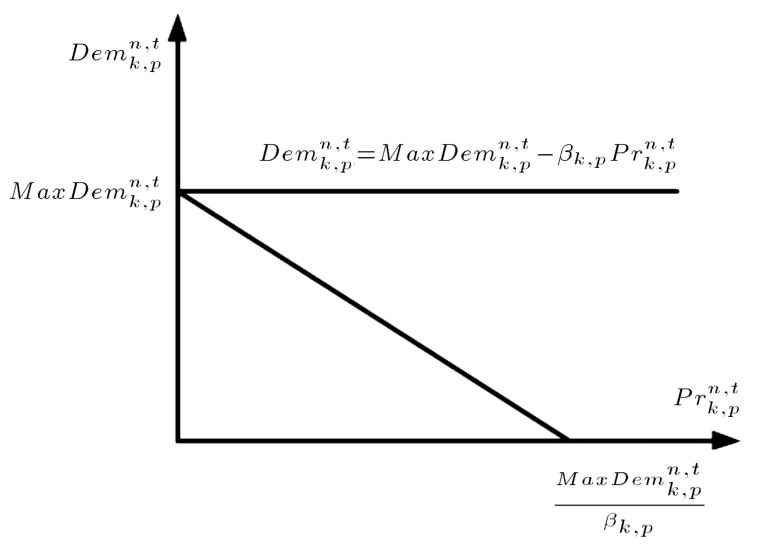

Figure 4. Selling price-dependent demand function. 


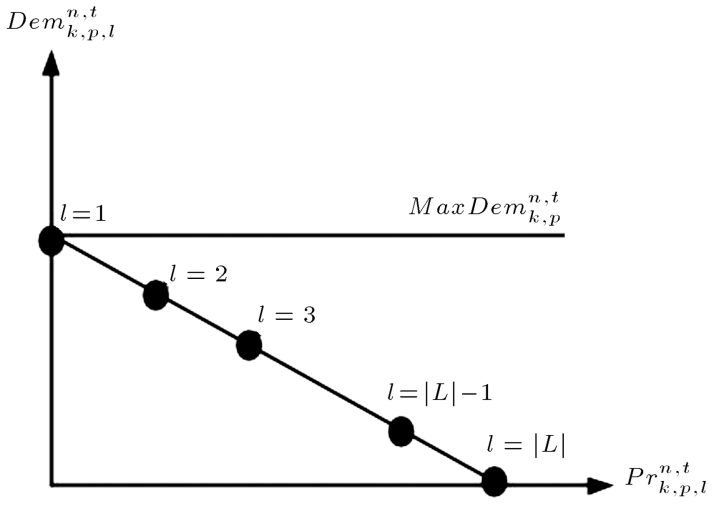

Figure 5. Discrete selling price and demand levels.

$$
\begin{aligned}
\operatorname{Dem}_{k, p}^{n, t} & =(1-\omega) \operatorname{Demand}_{k, p}^{n, t}-\beta_{k, p} \operatorname{Pr}_{k, p}^{n, t} \\
& =\operatorname{MaxDem}_{k, p}^{n, t}-\beta_{k, p} \operatorname{Pr}_{k, p}^{n, t} .
\end{aligned}
$$

It can be observed in Eq. (1) that the entrant supply chain can only meet a predefined portion of total demand $\left(\right.$ Demand $\left._{k, p}^{n, t}\right)$ in each customer zone $\left(\operatorname{MaxDem}_{k, p}^{n, t}\right)$.

The revenue earned from selling each product in each customer zone during each tactical period equals $\operatorname{Pr}_{k, p}^{n, t} \sum_{d} f_{d, k, p}^{n, t}$, which leads to nonlinearity in the model. Thus, a price leveling approach (see [6]) is used to have a linear relationship among decision variables. In this manner, different discrete price levels are considered for selling each product in each customer zone (see Figure 5). Assuming $L$ as the total number of price levels, the selling price value for level $l$ can be calculated using Eq. (2):

$$
\operatorname{Pr}_{k, p, l}^{n, t}=\frac{l-1}{L-1}\left(\frac{\operatorname{Max} \operatorname{Dem}_{k, p}^{n, t}}{\beta_{k, p}}\right)
$$

Finally, the revenue earned from selling each product in each customer zone during each tactical period can be calculated by $\operatorname{Pr}_{k, p, l}^{n, t}\left(\operatorname{Dem}_{k, p, l}^{n, t}-U_{k, p, l}^{n, t}\right)$.

\subsection{Buying price-dependent acquisition function}

In this paper, it is assumed that the quantity of return products depends linearly on buying price, which can be formulated as Eq. (3). Linear buying price-dependent acquisition functions are practically useful when buying price elasticity is high and small changes of buying price lead to considerable change in the amount of returned products $[22,23,26]$ :

$$
\operatorname{Ret}_{k, p}^{n, t}=\alpha \sum_{d \in D} f_{d, k, p}^{n, t}+\beta_{k, p}^{r} I \operatorname{Pr}_{k, p}^{n, t}
$$

The first term of Eq. (3) indicates the amount of returned products collected freely and the second term is additional returned products bought from customer

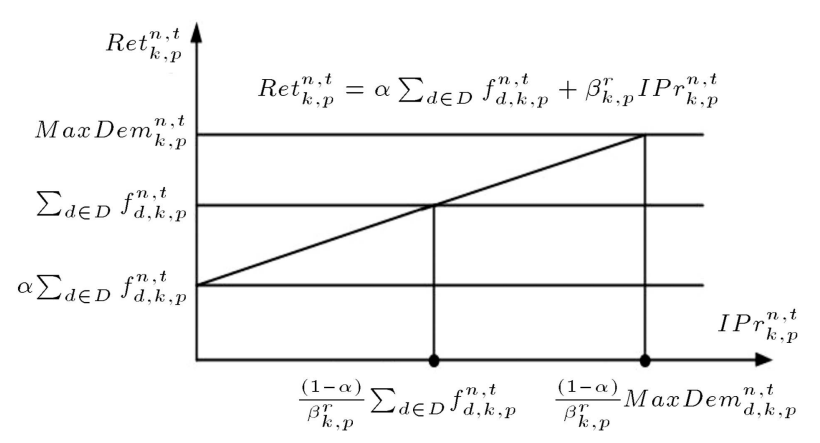

Figure 6. Buying price-dependent return product function.

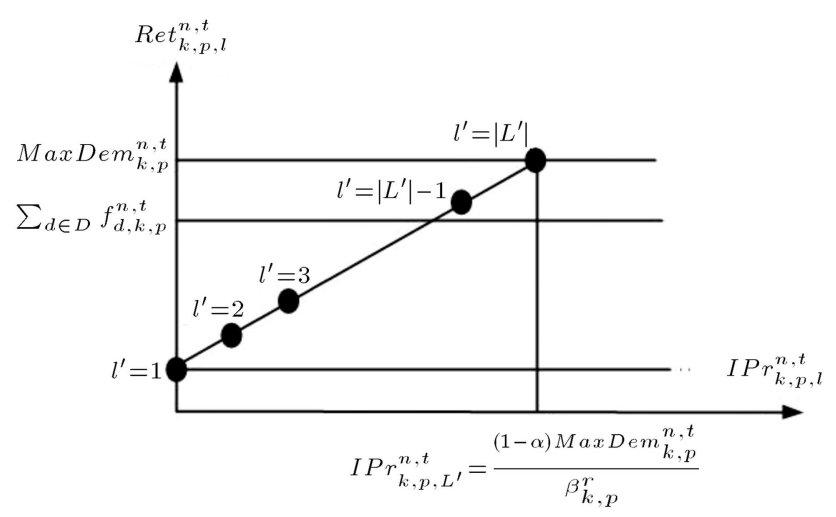

Figure 7. Buying price-dependent return product function.

zones regarding buying price. Figure 6 indicates the relationship between buying price and acquisition function of used product.

Similar to the leveling approach of sub-section 3.2, the nonlinear relationship in buying additional products $\left(\operatorname{IPr}_{k, p}^{n, t}\left(\beta_{k, p}^{r} I P r_{k, p}^{n, t}\right)\right)$ can be modified using different discrete levels for buying price (Figure 7). Assuming $L^{\prime}$ as the total number of buying price levels, the return price value for level $l^{\prime}$ can be calculated using Eq. (4):

$$
\operatorname{IPr}_{k, p, l^{\prime}}^{n, t}=\frac{l^{\prime}-1}{L^{\prime}-1}\left(\frac{(1-\alpha) \operatorname{MaxDem}_{k, p}^{n, t}}{\beta_{k, p}^{r}}\right) .
$$

Finally, the spent cost to buy additional returned products equals $I P r_{k, p, l^{\prime}}^{n, t}\left(\beta_{k, p}^{r} I P r_{k, o, l^{\prime}}^{n, t}\right)$. Since shortage can occur in each customer zone, Eq. (5) must be considered as an addition constraint to avoid selecting buying prices which lead to collecting products more than supplied demand:

$$
\begin{aligned}
& \sum_{l^{\prime}} \beta r_{k, p} I P r_{k, p, l^{\prime}}^{n, t} \varphi_{k, p, l^{\prime}}^{n, t} \leq(1-\alpha) \sum_{d \in D} f_{d, k}^{n, t} \\
& \forall k, p, n, t .
\end{aligned}
$$

\subsection{Model formulation}

In this sub-section, objective functions and constraints of the multi-objective model are described. 
3.4.1. Objective Functions (OF).

- First Objective Function: Economical OF (OF $)$. The first objective function of the proposed model is maximizing the total profit of the supply chain, which can be calculated by Eq. (6):

$$
M a x O F_{1}=\text { Income }_{\text {total }}-\text { Cost }_{\text {total }}+I R_{N} U B_{N} .
$$

The total income (Incometotal) is the revenue earned from selling products to customer zones in forward logistics plus the revenue earned by selling scrapped products to material customer zones in reverse logistics, which can be calculated using Eq. (7a):

$$
\begin{aligned}
\text { Income }_{\text {total }}= & \sum_{n \in N, n>0} \sum_{t \in T}\left(\sum_{k \in K} \sum_{p \in P} \sum_{l \in L} \operatorname{Pr}_{k, p, l}^{n, t}\right. \\
& \operatorname{Dem}_{k, p, l}^{n, t} \varepsilon_{k, p, l}^{n, t} \\
& \left.-\sum_{k \in K} \sum_{p \in P} \sum_{l \in L} \operatorname{Pr}_{k, p, l}^{n, t} S_{k, p, l}^{n, t}\right) \\
& +\sum_{n \in N, n>0} \sum_{t \in T} \sum_{c^{\prime} \in C^{\prime}} \sum_{r \in R} \sum_{p \in P} \\
& S V_{c^{\prime}, r, p} f_{c^{\prime}, r, p}^{n, t} .
\end{aligned}
$$

The total operating cost of closed-loop supply chain (Cost $\left._{\text {total }}\right)$ consists of fixed costs and variable cost, which can be calculated using Eqs. (7b) and (7c), respectively:

$$
\begin{aligned}
\text { Cost }_{\text {Fixed }}= & \sum_{n \in N, n>0} \sum_{m \in M} F O C_{m}^{n} O M_{m}^{n} \\
& +\sum_{n \in N, n>0} \sum_{d \in D} F O C_{d}^{n} O D_{d}^{n} \\
& +\sum_{n \in N, n>0} \sum_{c \in C} F O C_{c}^{n} O C_{c}^{n} \\
& +\sum_{n \in N, n>0} \sum_{r \in R} F O C_{r}^{n} O R_{r}^{n} \\
& +\sum_{n \in N, n>0} \sum_{t \in T} \sum_{o \in O} F C C_{m, o}^{n} \\
& \sum_{0<n^{\prime} \leq n} O_{m, o}^{n^{\prime}}, \\
\text { Cost }_{V a r}= & +\sum_{n \in N, n>0} \sum_{t \in T} \sum_{s \in S} \sum_{m \in M} \sum_{p^{\prime} \in P^{\prime}} B C_{s, p^{\prime}} f_{s, m, p^{\prime}}^{n, t} \\
+ & \sum_{n \in N, n>0} \sum_{t \in T} \sum_{m \in M} P C_{m, p} Q_{m, p}^{n, t}
\end{aligned}
$$

$$
\begin{aligned}
& +\sum_{n \in N, n>0} \sum_{t \in T} \sum_{d \in D} \sum_{p \in P} H C_{d, p}\left(H_{d, p}^{n, t}\right. \\
& \left.+\frac{1}{2} \sum_{m \in M} \frac{f_{m, d, p}^{n, t}}{A_{m, d}}+\frac{1}{2} \sum_{r \in R} \frac{f_{r, d, p}^{n, t}}{A_{r, d}}\right) \\
& +\sum_{n \in N, n>0} \sum_{t \in T} \sum_{k \in K} \sum_{p \in P} \sum_{l \in L} S C_{k, p} S_{k, p, l}^{n, t} \\
& +\sum_{n \in N, n>0} \sum_{t \in T} \sum_{k \in K} \sum_{p \in P} \sum_{l^{\prime} \in L^{\prime}} \beta_{k, p}^{r} \\
& \left(\operatorname{IPr}_{k, p, l^{\prime}}^{n, t}\right)^{2} \varphi_{k, p, l^{\prime}}^{n, t} \\
& +\sum_{n \in N, n>0} \sum_{t \in T} \sum_{c \in C} \sum_{r \in R} \sum_{p \in P}\left(I C_{r, p}\right. \\
& \left.+R C_{r, p} \gamma_{p}\right) f_{c, r, p}^{n, t} \\
& +\sum_{n \in N, n>0} \sum_{t \in T} \sum_{s \in S} \sum_{m \in M} \sum_{p^{\prime} \in P^{\prime}} \\
& T C_{s, m, p^{\prime}} f_{s, m, p^{\prime}}^{n, t} \\
& +\sum_{n \in N, n>0} \sum_{t \in T} \sum_{m \in M} \sum_{d \in D} \sum_{p \in P} T C_{m, d, p} f_{m, d, p}^{n, t} \\
& +\sum_{n \in N, n>0} \sum_{t \in T} \sum_{d \in D} \sum_{k \in K} \sum_{p \in P} T C_{d, k, p} f_{d, k, p}^{n, t} \\
& +\sum_{n \in N, n>0} \sum_{t \in T} \sum_{s \in S} \sum_{m \in M} \sum_{p^{\prime} \in P^{\prime}} T C_{k, c, p} f_{k, c, p}^{n, t} \\
& +\sum_{n \in N, n>0} \sum_{t \in T} \sum_{c \in C} \sum_{r \in R} \sum_{p \in P} T C_{c, r, p} f_{c, r, p}^{n, t} \\
& +\sum_{n \in N, n>0} \sum_{t \in T} \sum_{r \in R} \sum_{d \in D} \sum_{p \in P} T C_{r, d, p} f_{r, d, p}^{n, t} .
\end{aligned}
$$

Finally, the interest of investing unspent budget in foreign project for the last strategic period is equal to $I R_{N} U B_{N}$.

- Second Objective Function: Environmental OF $\left(O F_{2}\right)$. Recently, using Life Cycle Analysis (LCA) method, by which released waste is quantified through the product life cycle, makes considerable environmental performance possible for the firms [40]. In this paper, the total amount of harmful emissions, including released greenhouse gases (GHG), is considered as the second objective function, which can be formulated as Eq. (8): 
$\mathrm{MinOF}_{2}=$ Emission $_{\text {establishment }}$

$$
\begin{aligned}
& + \text { Emission }_{\text {operation }} \\
& + \text { Emission }_{\text {transportation }} .
\end{aligned}
$$

The establishment emissions include GHG emissions released due to opening facilities over the planning horizon, which can be formulated by Eq. (8a):

$$
\begin{gathered}
\text { Emission }_{\text {establishment }}=\sum_{m \in M} E_{m} O M_{m}^{N T} \\
+\sum_{d \in D} E_{d} O M_{d}^{N T}+\sum_{c \in C} E_{c} O C_{c}^{N T} \\
+\sum_{r \in R} E_{r} O R_{r}^{N T} .
\end{gathered}
$$

The operation emissions are the outcome of operating facilities, which indicate the amount of GHG emissions released by them. Eq. (8b) formulates these operation emissions:

$$
\begin{aligned}
& \text { Emission }_{\text {Operation }}=\sum_{n \in N, n>0} \sum_{t \in T} \sum_{m \in M} \sum_{p \in P} E P_{m, p} Q_{m, p}^{n, t} \\
& +\sum_{n \in N, n>0} \sum_{t \in T} \sum_{d \in D} \sum_{p \in P} E S_{d, p} H_{d, p}^{n, t} \\
& +\sum_{n \in N, n>0} \sum_{t \in T} \sum_{c \in C} \sum_{r \in R} \sum_{p \in P} E I_{r, p} f_{c, r, p}^{n, t} \\
& +\sum_{n \in N, n>0} \sum_{t \in T} \sum_{c \in C} \sum_{r \in R} \sum_{p \in P} E R_{r, p} \gamma_{p} f_{c, r, p}^{n, t} \quad(8 \mathrm{~b})
\end{aligned}
$$

The transportation GHG emissions arise from wasting energy to transport goods among facilities, as stated in Eq. (8c):

$$
\begin{aligned}
& \text { Emission }_{\text {Transportation }} \\
& =\sum_{n \in N, n>0} \sum_{t \in T} \sum_{s \in S} \sum_{m \in M} \sum_{p^{\prime} \in P^{\prime}} E T_{s, m, p^{\prime}} f_{s, m, p^{\prime}}^{n, t} \\
& +\sum_{n \in N, n>0} \sum_{t \in T} \sum_{m \in M} \sum_{d \in D} \sum_{p \in P} E T_{m, d, p} f_{m, d, p}^{n, t} \\
& +\sum_{n \in N, n>0} \sum_{t \in T} \sum_{d \in D} \sum_{k \in K} \sum_{p \in P} E T_{d, k, p} f_{d, k, p}^{n, t} \\
& +\sum_{n \in N, n>0} \sum_{t \in T} \sum_{k \in K} \sum_{c \in C} \sum_{p \in P} E T_{k, c, p} f_{k, c, p}^{n, t} \\
& +\sum_{n \in N, n>0} \sum_{t \in T} \sum_{c \in C} \sum_{r \in R} \sum_{p \in P} E T_{c, r, p} f_{c, r, p}^{n, t} \\
& +\sum_{n \in N, n>0} \sum_{t \in T} \sum_{r \in R} \sum_{d \in D} \sum_{p \in P} E T_{r, d, p} f_{r, d, p}^{n, t}
\end{aligned}
$$

$$
+\sum_{n \in N, n>0} \sum_{t \in T} \sum_{r \in R} \sum_{c^{\prime} \in C^{\prime}} \sum_{p \in P} E T_{r, c^{\prime}, p} f_{r, c^{\prime}, p}^{n, t} .
$$

- Third Objective Function: Social OF $\left(O F_{3}\right)$. The social aspect of sustainability considers the effects of firms on the society in which the firms operate [41]. One of the most common indicators used to determine the social concern is the number of job opportunities created by supply chains [13,27]. In this paper, maximizing the number of job opportunities is considered as the third objective function, which can be formulated by Eq. (9):

$$
\begin{aligned}
\operatorname{MaxOF}_{3}= & \sum_{m \in M} J_{m} O M_{m}^{N T}+\sum_{d \in D} J_{d} O M_{d}^{N T} \\
& +\sum_{c \in C} J_{c} O C_{c}^{N T}+\sum_{r \in R} J_{r} O R_{r}^{N T}
\end{aligned}
$$

\subsubsection{Constraints}

- Balance constraints:

$$
\begin{aligned}
& \sum_{s \in S} f_{s, m, p^{\prime}}^{n, t}=\sum_{p^{\prime} \in P^{\prime}} \rho_{p^{\prime}, p} Q_{m, p}^{n, t} \forall m, p, n>0, t, \\
& Q_{m, p}^{n, t}=\sum_{d \in D} f_{m, d, p}^{n, t} \forall m, p, n>0, t \\
& H_{d, p}^{n, t-1}+\sum_{m \in M} f_{m, d, p}^{n, t}+\sum_{r \in R} f_{r, d, p}^{n, t}=H_{d, p}^{n, t} \\
& +\sum_{k \in K} f_{d, k, p}^{n, t} \forall d, p, n, t \neq 1 \\
& H_{d, p}^{n-1, T}+\sum_{m \in N} f_{m, d, p}^{n, t}+\sum_{r \in R} f_{r, d, p}^{n, t}=H_{d, p}^{n, t} \\
& +\sum_{k \in K} f_{d, k, p}^{n, t} \forall d, p, n, t=1 \\
& \sum_{k \in K} f_{k, c, p}^{n, t}=\sum_{r \in R} f_{c, r, p}^{n, t} \forall c, p, n>0, t \\
& \gamma_{p} \sum_{c \in C} f_{c, r, p}^{n, t}=\sum_{d \in D} f_{r, d, p}^{n, t} \forall r, p, n>0, t>1, \\
& \gamma_{p} \sum_{c \in C} f_{c, r, p}^{n-1, T}=\sum_{d \in D} f_{r, d, p}^{n, t} \forall r, p, n>0, t=1 \\
& \left(1-\gamma_{p}\right) \sum_{c \in C} f_{c, r, p}^{n, t}=\sum_{c^{\prime} \in C^{\prime}} f_{r, c^{\prime}, p}^{n, t} \forall r, p, n>0, t .
\end{aligned}
$$

Constraint (10) ensures that each manufacturer buys sufficient raw material from different suppliers. Constraint (11) indicates that the manufactured product will be transported to distribution centers in each period. Constraints (12) and (13) balance the flow 
of products for DCs. Constraint (14) indicates that each collection center delivers all products collected from customer zones. Constraints (15)-(17) limit the products delivered from a recovery center with respect to recoverable fraction of the returned products.

Price-dependent demand constraints:

$$
\begin{aligned}
& \sum_{l \in L} \varepsilon_{k, p, l}^{n, t}=1 \forall k, p, n>0, t, \\
& S_{k, p, l}^{n, t} \leq \varepsilon_{k, p, l}^{n, t} \operatorname{Dem}_{k, p, l}^{n, t} \forall k, p, l, n>0, t, \\
& \sum_{d \in D} f_{d, k, l}^{n, t}+\sum_{l \in L} S_{k, p, l}^{n, t}=\sum_{l \in L} \varepsilon_{k, p, l}^{n, t} \operatorname{Dem}_{k, p, l}^{n, t} \\
& \forall p, n>0, t .
\end{aligned}
$$

Constraint (18) states that only one selling price level for each product in each customer zone and each period is possible. Regarding Constraint (19), the total number of shortages for a specific selling price level is less than the corresponding demand in each period. Constraint (20) limits sum of the delivered products and related shortages to corresponding demand for each selling price level.

Incentive price-dependent constraints:

$$
\begin{gathered}
\sum_{l^{\prime} \in L^{\prime}} \varphi_{k, p, l^{\prime}}^{n, t} \leq 1 \forall k, p, n>0, t \\
\sum_{l^{\prime} \in L^{\prime}} \beta r_{k, p} I P r_{k, p, l^{\prime}}^{n, t} \varphi_{k, p, l^{\prime}}^{n, t} \leq(1-\alpha) \\
\sum_{d \in D} f_{d, k}^{n, t} \forall k, p, n>0, t \\
\sum_{c \in C} f_{k, c, p}^{n, t}=\alpha \sum_{d \in D} f_{d, k, p}^{n, t}+\sum_{l^{\prime} \in L^{\prime}} \beta r_{k, p} I \operatorname{Pr}_{k, p, l^{\prime}}^{n, t} \varphi_{k, p, l^{\prime}}^{n, t} \\
\forall k, p, n>0, t
\end{gathered}
$$

Constraint (21) indicates that for each product, only one buying price level can be selected in each customer zone. Constraint (22) is the addition constraint, which limits selecting buying price with regards to the supplied demand. Constraint (23) indicates the amount of returned products in each period with regards to the buying price.

\section{Opening facilities constraints:}

$$
\begin{array}{ll}
O M_{m}^{n} \geq O M_{m}^{n-1} & \forall m, n>0, \\
O D_{d}^{n} \geq O D_{d}^{n-1} & \forall d, n>0, \\
O C_{c}^{n} \geq O C_{c}^{n-1} & \forall c, n>0, \\
O R_{r}^{n} \geq O R_{r}^{n-1} & \forall r, n>0 .
\end{array}
$$

Constraints (25)-(28) state that closing the opened facilities in the next periods is not possible.

Budget constraints:

$$
\begin{aligned}
& S B^{n}= \sum_{m \in M} F O_{m}^{n+1}\left(O M_{m}^{n+1}-O M_{m}^{n}\right) \\
&+\sum_{d \in D} F O_{d}^{n+1}\left(O D_{m}^{n+1}-O D_{m}^{n}\right) \\
&+\sum_{c \in C} F O_{c}^{n+1}\left(O C_{m}^{n+1}-O C_{m}^{n}\right) \\
&+\sum_{r \in R} F O_{r}^{n+1}\left(O R_{m}^{n+1}-O R_{m}^{n}\right) \\
&+\sum_{m \in M} \sum_{o \in O} F A_{m, o}^{n+1}\left(O_{m, o}^{n+1}\right) \forall n<N, \\
& S B^{n}+ U B^{n}=B^{n}+U B^{n-1} \\
& \forall n \in\{1,2, \ldots, N-1\}, \\
& S B_{n}+U B_{n}=B_{n} n=0, \\
& U B_{n}=I R_{n-1} U B_{n-1} n=N .
\end{aligned}
$$

Constraint (28) indicates the amount of spent budget in each strategic period, which depends on opening facilities and installing capacity options in the next strategic period. Constraints (29)-(31) state that the sum of spent and unspent budgets depends on the assigned budget and the unspent invested budget in the previous strategic period.

\section{Capacity constraints:}

$$
\sum_{o \in O} O_{m, o}^{n} \leq O M_{m}^{n}
$$$$
\forall m, n>0 \text {, }
$$

$$
\sum_{p \in P} U r_{m, p} Q_{m, p}^{n, t} \leq U_{m} \sum_{n^{\prime} \leq n, n^{\prime} \in N} \sum_{o \in O} \operatorname{Exp}_{m, o} O_{m, o}^{n^{\prime}}
$$

$$
\sum_{n^{\prime} \leq n, n^{\prime} \in N} \sum_{o \in O} \operatorname{Exp}_{m, o} O_{m, o}^{n^{\prime}} \leq \operatorname{Cap}_{m}^{\max }
$$

$$
\forall m, n>0,
$$




$$
\begin{aligned}
& \sum_{p} U r_{p} H_{d, p}^{n, t}+\frac{1}{2} \sum_{m \in M} \sum_{p \in P} U r_{p} \frac{f_{m, d, p}^{n, t}}{A_{m, d}} \\
&+\frac{1}{2} \sum_{m \in M} \sum_{p \in P} U r_{p} \frac{f_{r, d, p}^{n, t}}{A_{r, d}} \leq O D_{d}^{n} C a p_{d}^{\max } \\
& \forall d, n>0, t, \\
& \sum_{k \in K} \sum_{p \in P} f_{k, c, p}^{n, t} \leq O C_{c}^{n} C a p_{c}^{\max } \forall c, n>0, t \\
& \sum_{c \in C} \sum_{p \in P} f_{c, r, p}^{n, t} \leq O R_{r}^{n} C a p_{r}^{\max } \forall r, n>0, t .
\end{aligned}
$$

According to Constraint (32), each manufacturer can operate under only one capacity option during each strategic period. Constraints (33)-(37) indicate the maximum capacity of facilities.

Decision variable constraints:

$$
\begin{aligned}
& O M_{m}^{n}, O D_{d}^{n}, O C_{c}^{n}, O R_{r}^{n}, O_{m, o}^{n}, \varepsilon_{k, p, l}^{n, t}, \varphi_{k, p, l^{\prime}}^{n, t}=\{0,1\} \\
& Q_{m, p}^{n, t}, H_{d, p}^{n, t}, f_{s, m, p^{\prime}}^{n, t}, f_{i, j, p}^{n, t}, S_{k, p, l}^{n, t}, U B_{n} \geq 0
\end{aligned}
$$

Constraint (38) indicates the decision variables.

\section{Multi-objective Pareto-based meta-heuristic algorithm}

In the recent years, multi-objective Pareto-based metaheuristic algorithms have been used as a main solution approach for problems with conflicting goals. In multiobjective problems, there are $m$ objective functions such as $O F(\vec{x})=\left[O F_{1}(\vec{x}), \ldots, O F_{m}(\vec{x})\right]$ and $c$ constraints such as $g_{i}(\vec{x}) \leq 0, i=1,2, \ldots, c, \vec{x} \in X$ in which $\vec{x}$ and $X$ indicate the $n$-dimensional solution vector and feasible region, respectively. There is normally confliction among some goals in a multi-objective problem, which leads to domination concept. For maximization problem, solution $\vec{a}$ dominates solution $\vec{b}(\vec{a}, \vec{b} \in X)$ if:

1. $f_{i}(\vec{a}) \geq f_{i}(\vec{b}), \quad \forall i=1,2, \ldots, m$

2. $\exists i \in\{1,2, \ldots, m\}: f_{i}(\vec{a})>f_{i}(\vec{b})$.

The solutions which cannot dominate each other are called Pareto front. In a Pareto front, the goodness of different solutions can be evaluated regarding convergence and diversity of the solutions [42].

Based on complexity of the proposed model, especially in large-size cases, a multi-objective Pareto-based meta-heuristic algorithm, called MOICA, has been used to solve the proposed model and its results have been compared with those of an NSGA-II algorithm. In the following sub-sections, these two algorithms are described.

\subsection{Multi-Objective Imperialist Competitive Algorithm (MOICA)}

One of the evolutionary algorithms widely attended to during the last years has been Imperialist Competitive Algorithm (ICA). ICA, which has been introduced by Atashpaz-Gargari et al. [43], is based on the imperialism phenomenon.

The ability of ICA in finding good solution to single-objective models leads researchers to use ICA for multi-objective problems. The multi-objective version of the imperialist competitive algorithm (MOICA) has been developed by Enayatifar et al. [44].

In this paper, MOICA is used to solve the proposed multi-objective model. The steps of the proposed MOICA are as follow:

- Step 1: Initializing the empires. As the first step, $N_{\text {pop }}$ countries (number of population) should be created. Figure 8 indicates the proposed solution representation. Accordingly, each solution includes the following three parts:

- Part 1: The first part of each solution, which is related to strategic decisions, is a $1 \times(M+$ $D+C+R$ ) vector. The cells of this vector show manufacturers, DCs, CCs, and recovery centers, respectively. This vector indicates the strategic period in which the related facility should be opened. Zero value for each cell indicates that the related facility will be closed;

- Part 2: The second part is an $M \times N$ matrix, which indicates the capacity option activated for the related manufacturer in the related strategic period;

- Part 3: The third part includes a $2 P \times K \times T \times N$ super-matrix, which determines the selling and buying price levels of the related product for relevant customer zone in related tactical periods of each strategic period.

The other continuous tactical decision variables for each solution will be created, randomly, based on these values.

After initialization of $N_{\text {pop }}$ countries, $N_{i m p}$ of them, which are more powerful, should be selected as imperialists. The remaining are known as colonies of the imperialists. For a multi-objective problem, the power of each imperialist should be calculated regarding two criteria:

(1) Rank of each country based on Fast NonDominated Sorting (FNDS) technique;

(2) Merit of each country compared to countries with the same rank, based on crowding distance criterion.

According to [44], the power of each country 


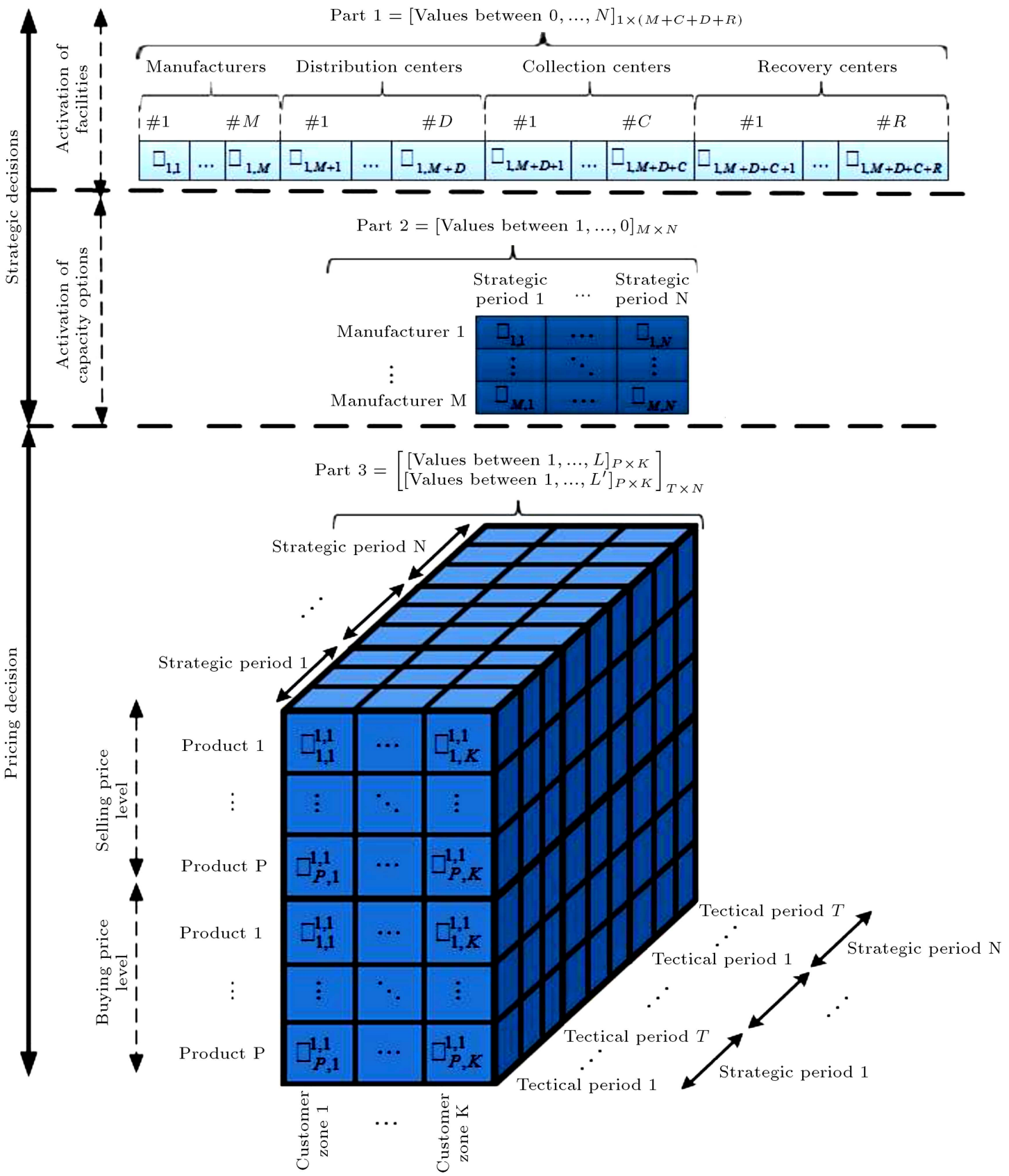

Figure 8. Solution representation.

can be calculated using Eq. (39):

power $_{n}=$

$\frac{1}{\sum_{j=1}^{D}\left[O F_{j}(n) / \sum_{i=1}^{N_{\text {rank }}(C)} O F_{j}(i)\right](\operatorname{Rank}(C)-1) \times D^{(39)}}$

where $D$ is the number of objective functions, $O F_{j}(i)$ is the value of the $j$ th objective function of country $i$, and $N_{\text {rank }}(C)$ is the number of countries in rank $C$.

The number of countries assigned to each imperialist (NC) can be calculated using Eq. (40):

$$
N C_{n}=\text { round }\left\{p_{n} N_{c o l}\right\} \text {, }
$$

where $p_{n}=\left|\frac{\text { power }_{n}}{\sum_{i=1}^{N_{\text {imp }} \text { power }} i}\right|$ indicates the imperialists power ratio.

- Step 2: Moving of the colonies toward their imperialist. Colonies move toward their imperialist position, with a small deviation. The movement of colonies $(x)$ and possible deviation in this movement $(\theta)$ can be calculated using Eqs. (41) and (42), respectively: 


$$
\begin{aligned}
& x \sim U(0, \beta \times d), \\
& \theta \sim U(-\gamma, \gamma),
\end{aligned}
$$

where $U($.$) is a random variable, which has a uniform$ distribution, $d$ is the distance between each colony and its imperialist, and $\beta$ and $\gamma$ are two predefined parameters of the algorithm.

- Step 3: Exchanging position of imperialist and colony. If a colony reaches a better position than its imperialist after movement, an exchange between the current colony and its imperialist should be applied.

- Step 4: Computing the total cost of all empires. The overall power of each empire depends on the power of its imperialist and mean power of its colonies, which can be calculated using Eq. (43):

$$
\begin{aligned}
T C_{n}= & \operatorname{Cost}\left(\text { imperialist }_{n}\right) \\
& +\zeta \text { mean }\{\cos t(\text { colonies })\}
\end{aligned}
$$

where $\zeta$ is a positive number less than 1 .

- Step 5: Imperialist competition. During this step, the most powerful empire attempts to seize the weakest colony of the weakest empire. To calculate the normalized power of each empire $\left(N T C_{n}\right)$ regarding their total cost, Eq. (44) can be used:

$$
N T C_{n}=T C_{n}-\max \left\{T C_{n}\right\}
$$

- Step 6: Eliminating the powerless empires The empire which has lost all its colonies should be eliminated.

\section{Stop condition}

After each iteration, the number of empires will be checked, first. If there is only one empire, the algorithm will stop. Moreover, if the number of iterations exceeds the maximum number of iterations, the algorithm will stop.

The flowchart of the proposed MOICA is shown in Figure 9, in which the multi-objective parts are indicated by different colors.

\subsection{NSGA-II algorithms}

One of the well-known meta-heuristic algorithms is Non-dominated Sorting Genetic Algorithm (NSGA), which was developed by Srinivas and Deb [45]. Respecting weaknesses of NSGA, Deb et al. [42] introduced an extension to NSGA, called NSGA-II.

In this paper, NSGA-II algorithm is used as a second meta-heuristic algorithm to solve the proposed closed-loop supply chain network design problem. The flowchart of the proposed NSGA-II is depicted in Figure 9 .

\section{Results analysis}

To study the performance of algorithms, the following metrics have been used:

- The CPU time of algorithms to achieve nearoptimum solutions;

- The number of solutions in Pareto optimal front; larger value is better;

- Diversity, which indicates the extension of the Pareto front [46]; larger value is better;

- Spacing, which indicates the standard deviation of the distances among solutions of the Pareto front [47]; smaller value is better;

- Mean ideal distance (MID), which is the distance among Pareto fronts and an ideal solution [46]; smaller value is better.

The algorithms will be experimented for 20 generated test problems, of which the characteristics are indicated in Table 2.

To adjust the parameters of the algorithms, Taguchi method is used. This method attempts to minimize the noise effect and determine an optimal level of signal factors using signal to noise ratio [48-49]. Table 3 indicates different levels of factors for MOICA and NSGA-II [50]. Then, the L9 design and L27 design are implemented for NSGA-II and MOICA, respectively,

Table 2. Characteristics of test problems.

\begin{tabular}{cccccccccccccc}
\hline Problem no. $\boldsymbol{S}$ & $\boldsymbol{M}$ & $\boldsymbol{D}$ & $\boldsymbol{K}$ & $\boldsymbol{C}$ & $\boldsymbol{R}$ & $\boldsymbol{C}^{\prime}$ & $\boldsymbol{P}^{\prime}$ & $\boldsymbol{P}$ & $\boldsymbol{O}$ & $\boldsymbol{N}$ & $\boldsymbol{T}$ \\
\hline P1 & 1 & 2 & 2 & 2 & 1 & 1 & 1 & 2 & 1 & 2 & 1 & 3 \\
$\mathbf{P 2}$ & 1 & 2 & 3 & 2 & 2 & 1 & 1 & 2 & 1 & 2 & 2 & 3 \\
P3 & 2 & 2 & 3 & 2 & 2 & 2 & 1 & 2 & 2 & 2 & 2 & 3 \\
P4 & 2 & 2 & 4 & 3 & 2 & 2 & 1 & 2 & 2 & 2 & 2 & 3 \\
P5 & 3 & 3 & 4 & 4 & 3 & 3 & 1 & 2 & 2 & 2 & 2 & 3 \\
P6 & 3 & 3 & 5 & 4 & 3 & 4 & 2 & 3 & 3 & 2 & 2 & 3 \\
P7 & 3 & 4 & 5 & 5 & 3 & 4 & 2 & 3 & 3 & 2 & 3 & 3 \\
P8 & 4 & 5 & 6 & 6 & 4 & 4 & 3 & 4 & 3 & 2 & 3 & 3 \\
P9 & 4 & 6 & 6 & 7 & 4 & 4 & 3 & 4 & 4 & 2 & 3 & 3 \\
P10 & 4 & 6 & 7 & 8 & 4 & 5 & 3 & 5 & 4 & 2 & 3 & 3 \\
P11 & 4 & 7 & 7 & 9 & 5 & 6 & 3 & 5 & 4 & 2 & 3 & 3 \\
P12 & 5 & 7 & 8 & 10 & 5 & 6 & 3 & 6 & 4 & 3 & 3 & 3 \\
P13 & 5 & 8 & 9 & 10 & 5 & 6 & 3 & 7 & 4 & 3 & 3 & 3 \\
P14 & 5 & 9 & 10 & 10 & 6 & 7 & 3 & 8 & 5 & 3 & 3 & 3 \\
P15 & 5 & 9 & 11 & 12 & 7 & 7 & 3 & 8 & 5 & 3 & 4 & 3 \\
P16 & 6 & 9 & 12 & 13 & 7 & 8 & 3 & 9 & 5 & 3 & 4 & 3 \\
P17 & 6 & 10 & 12 & 15 & 7 & 8 & 3 & 9 & 5 & 3 & 4 & 3 \\
P18 & 7 & 10 & 13 & 16 & 8 & 8 & 3 & 9 & 6 & 3 & 4 & 3 \\
P19 & 8 & 11 & 13 & 18 & 8 & 8 & 4 & 9 & 7 & 3 & 4 & 3 \\
P20 & 10 & 15 & 15 & 20 & 10 & 10 & 5 & 10 & 10 & 4 & 5 & 3 \\
\hline
\end{tabular}




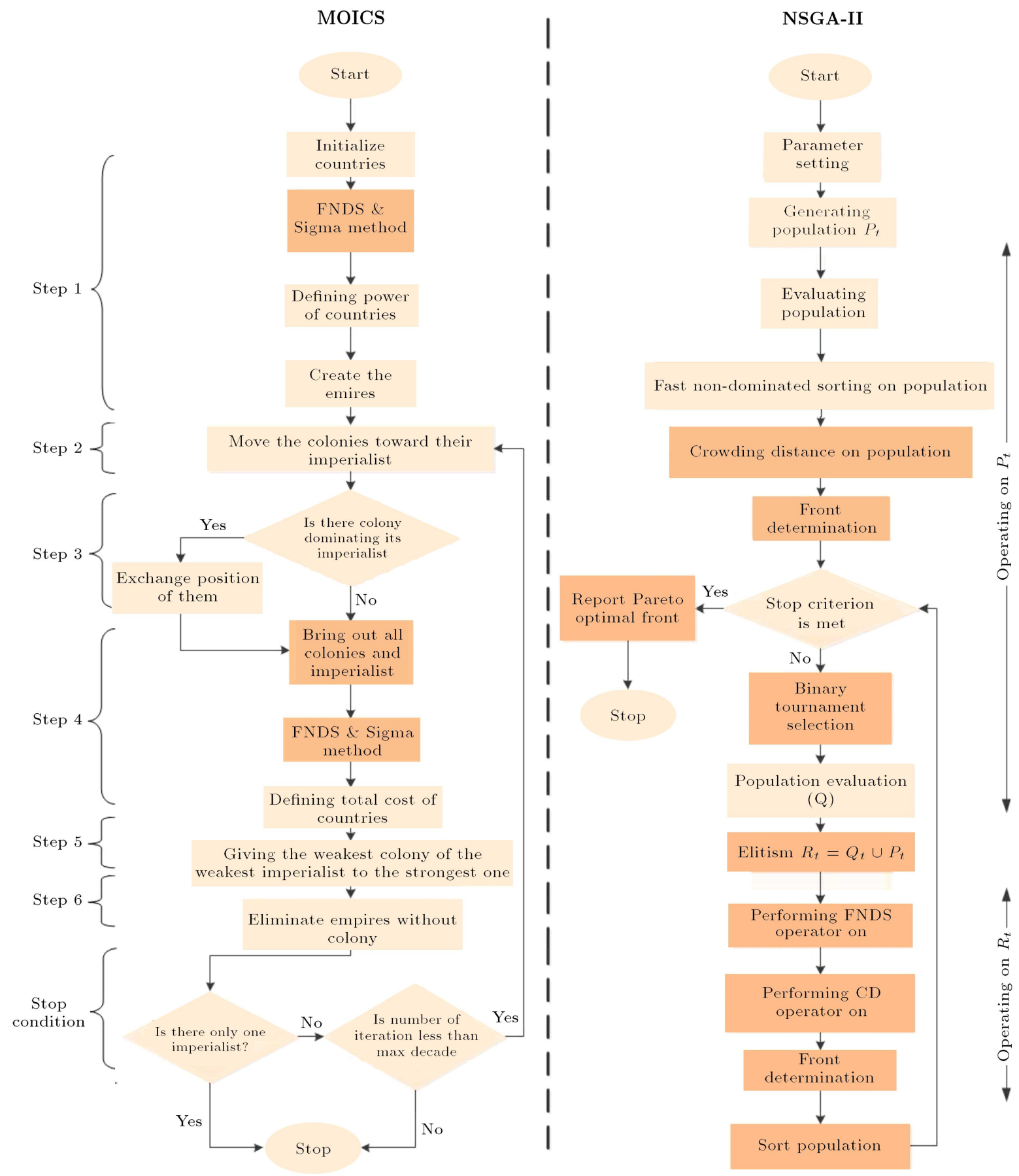

Figure 9. Flowchart of MOICA and NSGA-II.

using Minitab Software. Figure 10 indicates the effect plot of signal to noise ratio for algorithms. As larger value for this ratio is better, the proper level of each parameter is highlighted in Table 3.

The generated problems have been solved using algorithms and the results are reported in Table 4. To code the algorithms, MATLAB Software (Version 7.10.0.499, R2010a) on a $2 \mathrm{GHz}$ laptop with 8 GB RAM is used [51].

In order to evaluate the performance of the proposed MOICA, the following analyses are carried out.

\subsection{Statistical analysis}

To statistically compare similarities in performances of the algorithms, analysis of variance (ANOVA) test is executed for each metric and the results are shown in Table 5. The individual plots are depicted in Figure 11. Figure 12 indicates the performance of algorithms with respect to all test problems for each metric. 
Table 3. Algorithm parameter ranges along with values of algorithm parameters.

\begin{tabular}{|c|c|c|c|c|}
\hline \multirow{2}{*}{$\begin{array}{l}\text { Multi-objective } \\
\text { algorithms }\end{array}$} & \multirow{2}{*}{$\begin{array}{l}\text { Algorithm } \\
\text { parameters }\end{array}$} & \multicolumn{3}{|c|}{ Parameter levels } \\
\hline & & Low & Middle & High \\
\hline \multirow{6}{*}{ MOICA } & Number of population & 20 & 30 & 40 \\
\hline & Number of imperialists & 5 & 10 & 15 \\
\hline & A random variable & 1 & 2 & 3 \\
\hline & Deviation form original direction & 0.5 & 0.6 & 0.7 \\
\hline & Influence coefficient of colonies & 0.05 & 0.1 & 0.2 \\
\hline & Maximum generation & 50 & 100 & 200 \\
\hline \multirow{4}{*}{ NSGA-II } & Number of population & 20 & 25 & 30 \\
\hline & Crossover probability & 0.5 & 0.55 & 0.6 \\
\hline & Mutation probability & 0.35 & 0.4 & 0.45 \\
\hline & Maximum number of generations & 50 & 75 & 100 \\
\hline
\end{tabular}

Table 4. Multi-objective metrics computed for the proposed Pareto-based meta-heuristics.

\begin{tabular}{|c|c|c|c|c|c|c|c|c|c|c|}
\hline \multirow{3}{*}{$\begin{array}{c}\text { Problem } \\
\text { no. }\end{array}$} & \multicolumn{10}{|c|}{ Algorithm } \\
\hline & \multicolumn{5}{|c|}{ NSGA-II } & \multicolumn{5}{|c|}{ MOICA } \\
\hline & Spacing & MID & Diversity & NOS & Time & Spacing & MID & Diversity & NOS & Time \\
\hline 1 & 0.7173 & 1.0273 & 3422.5973 & 12 & 26.8771 & 1.0988 & 1.0247 & 1181.6300 & 17 & 18.7065 \\
\hline 2 & 0.5502 & 1.1925 & 5061.3190 & 13 & 47.0899 & 1.1574 & 0.9769 & 1143.5122 & 16 & 37.5912 \\
\hline 3 & 0.4296 & 0.9190 & 4088.1627 & 15 & 82.7915 & 1.1819 & 0.8953 & 3506.4638 & 17 & 76.4658 \\
\hline 4 & 0.5576 & 1.0217 & 6315.6232 & 15 & 117.8210 & 1.1543 & 0.9515 & 4609.8030 & 22 & 107.5754 \\
\hline 5 & 0.6861 & 0.8967 & 7227.0165 & 21 & 149.6871 & 1.1017 & 0.8685 & 4978.6797 & 23 & 137.0491 \\
\hline 6 & 0.4481 & 1.0566 & 8006.8991 & 17 & 225.4818 & 1.0215 & 1.0161 & 3992.4625 & 24 & 213.3122 \\
\hline 7 & 0.4124 & 1.0694 & 11428.1502 & 17 & 395.4545 & 1.5164 & 1.0041 & 6717.8032 & 28 & 373.2581 \\
\hline 8 & 0.4641 & 1.2191 & 13061.0248 & 17 & 512.6571 & 1.1468 & 1.1070 & 4881.2655 & 26 & 467.1043 \\
\hline 9 & 0.4724 & 1.3450 & 16152.3872 & 15 & 779.2661 & 1.0205 & 1.2748 & 3196.5109 & 19 & 774.1683 \\
\hline 10 & 0.4560 & 1.3236 & 17098.1189 & 17 & 945.8829 & 1.1360 & 1.2938 & 7812.9618 & 24 & 767.9396 \\
\hline 11 & 0.5849 & 1.3252 & 17963.4208 & 15 & 1021.4184 & 1.0699 & 1.3240 & 3942.7870 & 18 & 975.6648 \\
\hline 12 & 0.4867 & 1.2671 & 23870.8514 & 22 & 1231.9429 & 1.6591 & 1.3290 & 13153.3171 & 27 & 1108.4170 \\
\hline 13 & 0.3519 & 1.2261 & 19560.1163 & 24 & 1362.6252 & 1.4471 & 1.3362 & 14359.0873 & 26 & 1303.6427 \\
\hline 14 & 0.5093 & 1.1228 & 29819.2891 & 21 & 1675.1914 & 1.6199 & 1.2018 & 10478.0737 & 27 & 1589.9950 \\
\hline 15 & 0.6766 & 1.1271 & 39362.9892 & 18 & 2786.5877 & 1.7606 & 1.2672 & 12902.1185 & 21 & 2608.6909 \\
\hline 16 & 0.5274 & 1.1204 & 31303.9707 & 21 & 3161.3055 & 1.4752 & 1.2197 & 8549.7959 & 24 & 2993.6367 \\
\hline 17 & 0.6148 & 1.1207 & 41340.3515 & 25 & 3522.7108 & 1.7402 & 1.2038 & 14939.9158 & 28 & 3289.9307 \\
\hline 18 & 0.6324 & 1.1171 & 47510.2721 & 18 & 5119.7896 & 1.0235 & 1.2141 & 4617.7268 & 19 & 4420.7271 \\
\hline 19 & 0.4775 & 1.0938 & 47184.2364 & 21 & 8331.8567 & 1.8925 & 1.1221 & 30579.2631 & 25 & 7238.5271 \\
\hline 20 & 0.6524 & 1.1059 & 48419.3471 & 22 & 13284.8567 & 1.3393 & 1.1232 & 35463.2368 & 24 & 11469.5271 \\
\hline
\end{tabular}


Table 5. The $P$-values of the analysis of variance comparison test.

\begin{tabular}{cccc}
\hline Metric's name & P-value & Test results & Rank $^{*}$ \\
\hline Diversity & 0.00 & Null hypothesis is rejected & MOICA $<$ NSGA-II \\
MID & 0.94 & Null hypothesis is not rejected & MOICA $~$ NSGA-II \\
Spacing & 0.04 & Null hypothesis is rejected & MOICA $<$ NSGA-II \\
NOS & 0.01 & Null hypothesis is rejected & MOICA $>$ NSGA-II \\
Time & 0.81 & Null hypothesis is not rejected & MOICA $~$ NSGA-II \\
\hline
\end{tabular}

* Bigger is better

Table 6. Pareto solutions to problem no. 9 along with non-domination analysis.

\begin{tabular}{|c|c|c|c|c|c|c|c|}
\hline \multirow{2}{*}{$\begin{array}{c}\text { Pareto } \\
\text { solution no. }\end{array}$} & \multicolumn{3}{|c|}{ MOICA } & \multicolumn{3}{|c|}{ NSGA-II } & \multirow{2}{*}{$\begin{array}{l}\text { The solutions to } \\
\text { MOICA dominate } \\
\text { current solution } \\
\text { to NSGA-II }\end{array}$} \\
\hline & $O F_{1}$ & $\mathrm{OF}_{2}$ & $O F_{3}$ & $O F_{1}$ & $O F_{2}$ & $O F_{3}$ & \\
\hline 1 & 21836429 & 24640493 & 2097 & 23304093 & 26089642 & 1170 & $4,10,17$ \\
\hline 2 & 21474892 & 23640471 & 2031 & 13331776 & 16541498 & 1805 & \\
\hline 3 & 21094493 & 23240340 & 2017 & 22216107 & 26406264 & 1546 & $4,8,10,11,15,17,18$ \\
\hline 4 & 24947924 & 25639922 & 1686 & 17538973 & 23504410 & 2165 & \\
\hline 5 & 24038914 & 26640182 & 1851 & 9014768 & 17325311 & 1979 & \\
\hline 6 & 21497543 & 22640095 & 1733 & 18249127 & 22966637 & 880 & $5,6,7,9,13$ \\
\hline 7 & 21378478 & 22640281 & 1896 & 11019483 & 17749084 & 1881 & \\
\hline 8 & 22726939 & 23140157 & 1751 & 18500872 & 23392446 & 1020 & $3,5,6,7,8,9,13,15$ \\
\hline 9 & 21210592 & 21640256 & 1827 & 18963445 & 24566851 & 1699 & $2,3,5,6,7,8,9,10,12,13,14,15,19$ \\
\hline 10 & 23647843 & 24240156 & 1909 & 15675774 & 19498973 & 2113 & \\
\hline 11 & 23129184 & 26040421 & 2076 & 19718498 & 23850372 & 1432 & $2,3,5,6,7,8,9,13,15$ \\
\hline 12 & 22136998 & 24140207 & 2088 & 20660876 & 24122878 & 1160 & $2,3,5,6,7,8,9,13,14,15,19$ \\
\hline 13 & 20894907 & 22940340 & 2021 & 20704188 & 25518042 & 1513 & $1,2,3,5,6,7,8,9,10,12,13,14,15,18,19$ \\
\hline 14 & 21127329 & 23940523 & 2142 & 16304449 & 19834607 & 1217 & \\
\hline 15 & 22276353 & 23110239 & 1891 & 16635795 & 19951278 & 1294 & \\
\hline 16 & 24117380 & 27105769 & 2085 & & & & \\
\hline 17 & 25707906 & 26035772 & 1760 & & & & \\
\hline 18 & 23111298 & 24856749 & 2113 & & & & \\
\hline 19 & 22107940 & 23851486 & 1954 & & & & \\
\hline
\end{tabular}

Based on the statistical outputs shown in Table 5 along with Figure 11, MOICA shows better performance in terms of NOS, while NSGA-II is better regarding spacing and diversity metrics. Moreover, they show the comparability of MOICA with NSGA-II in terms of MID and time metrics. These conclusions are confirmed at 95\% confidence level. Figure 12 confirmed the abovementioned conclusions.
Figure 13 indicates how fast MOICA is in comparison with NSGA-II. It can be observed that MOICA is faster than NSGA-II in solving large-size problems.

\subsection{Performance of MOICA and NSGA-II}

To compare the results of MOICA and NSGA-II, non-dominated solutions to algorithms are compared. Table 6 represents the Pareto-front of algorithms for 

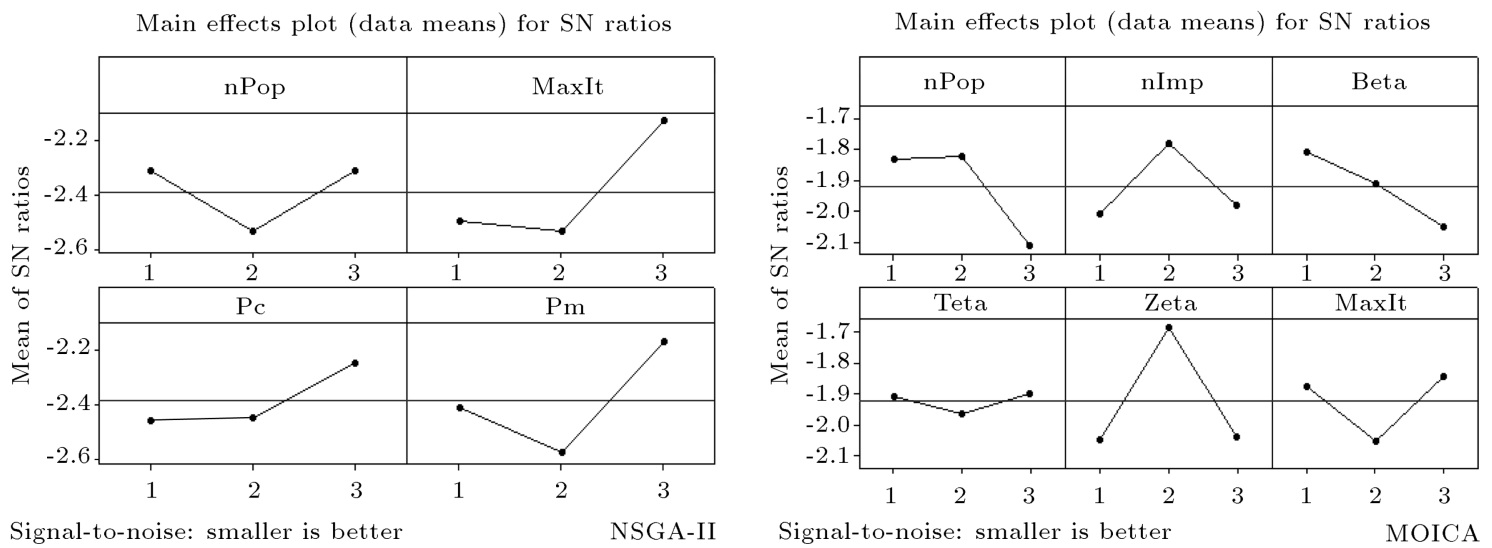

Figure 10. Taguchi outputs for algorithms.
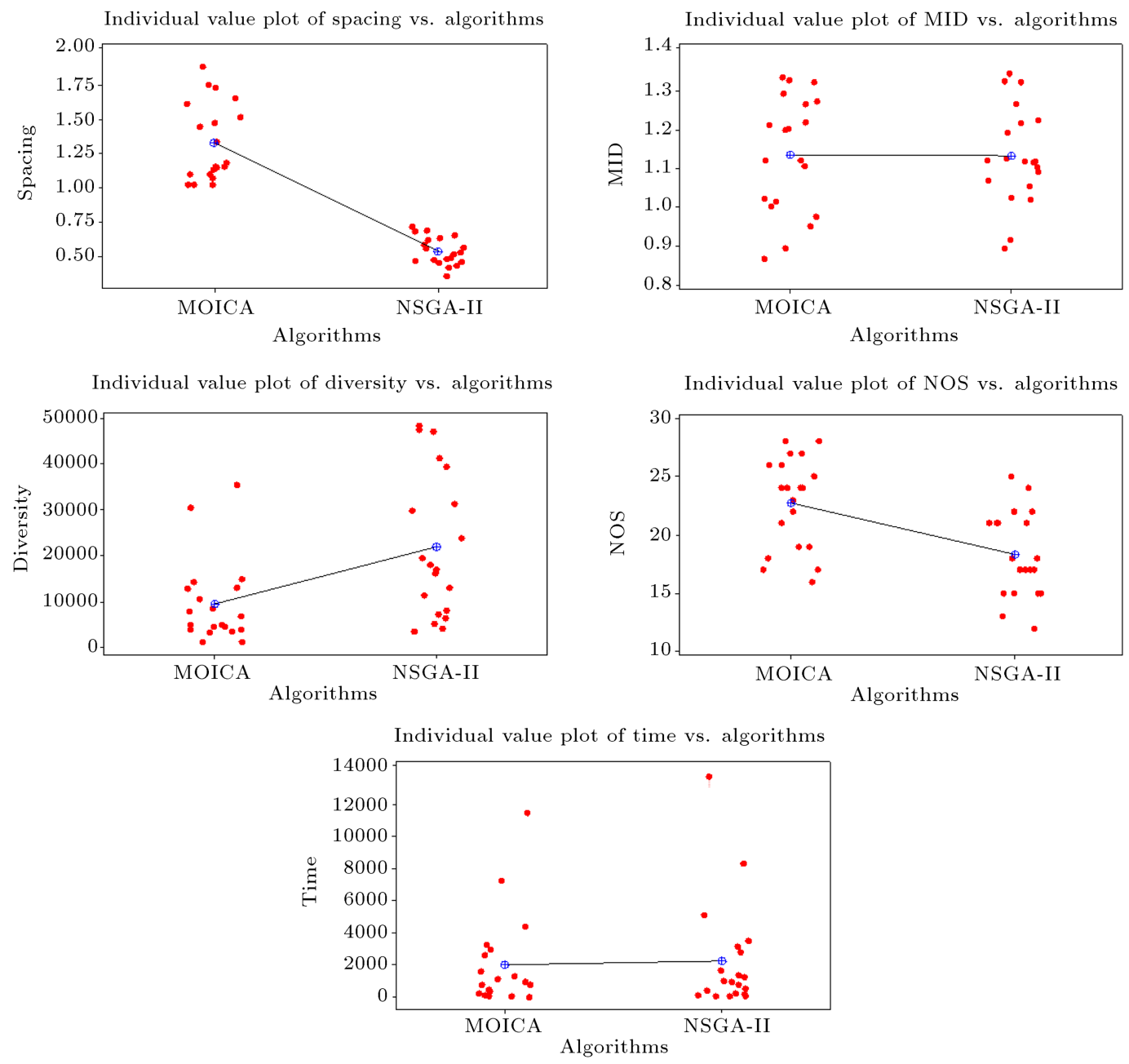

Figure 11. Individual value plot of multi-objective metrics vs. algorithms.

problem no. 9. The results of NSGA-II, which have been dominated by results of MOICA, can be observed in Table 6. For example, result no. 1 of NSGA-II is dominated by results no. 4, 10, and 17 of MOICA.

Finally, the Pareto solutions to problems no. 9 and 14 for both algorithms are indicated in Figure 14.

\section{Conclusion}

In this paper, a novel multi-objective closed-loop SCND model was presented. The main characteristics of this paper are as follow:

- The goals of the proposed model were maximizing 

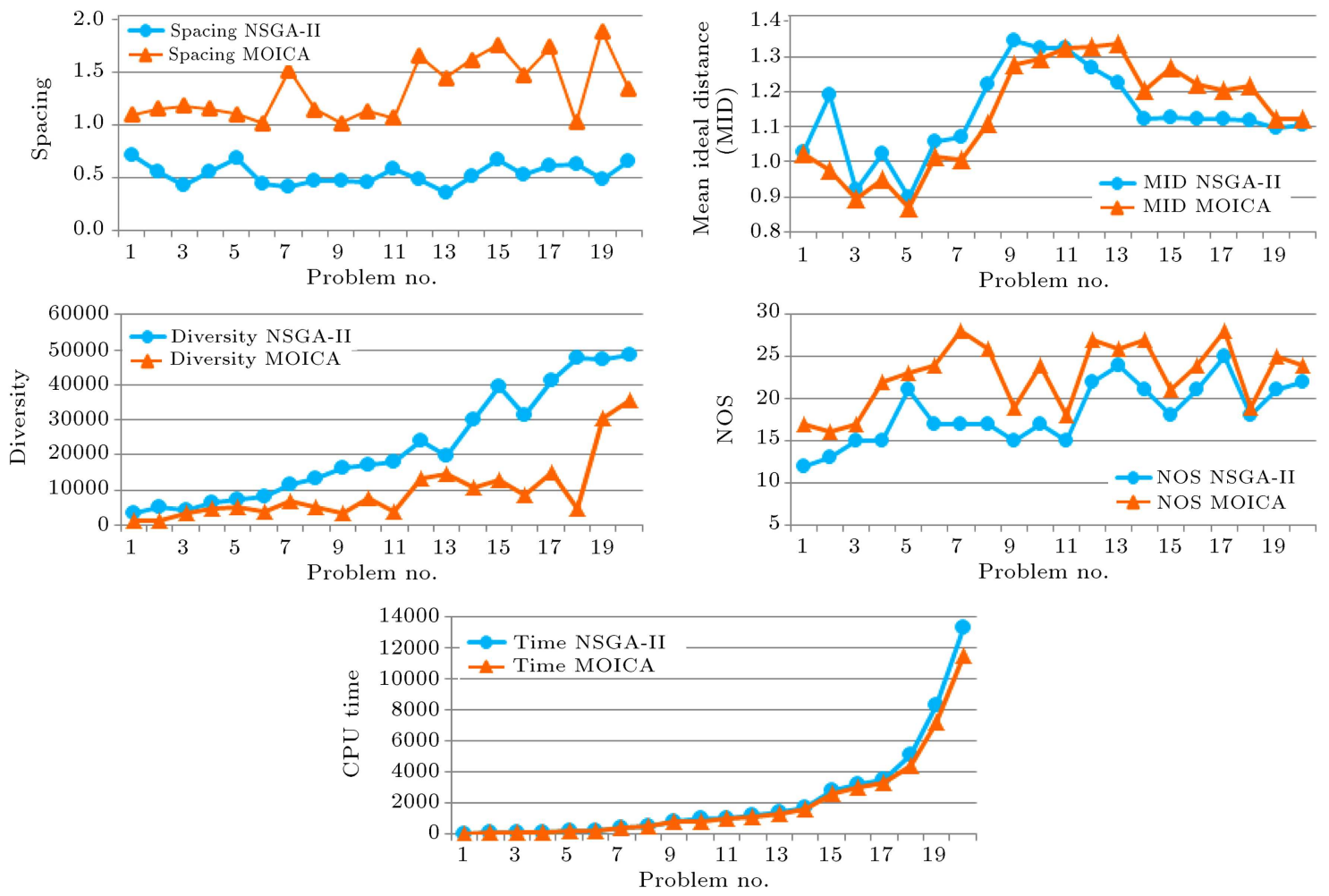

Figure 12. Graphical comparisons of the algorithms.

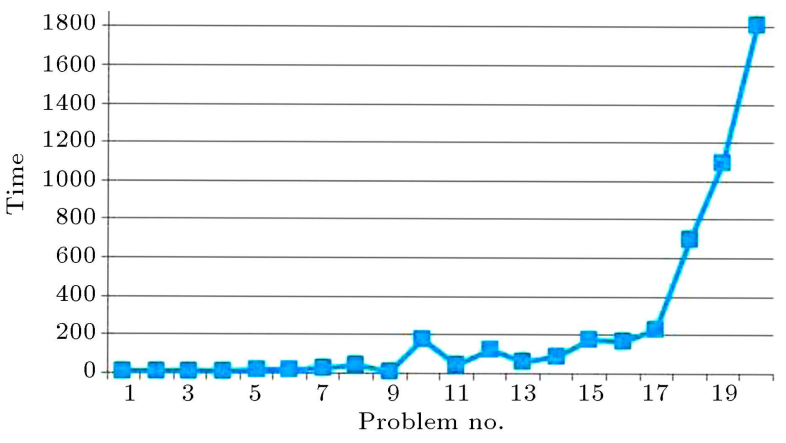

Figure 13. CPU time difference among algorithms. the profit, minimizing environmental emissions, and maximizing job creation related to social concern, simultaneously;

- Multiple strategic periods, which consisted of several tactical periods, were considered in the proposed dynamic SCND problem;

- In addition to several tactical decisions, integrated by the strategic supply chain design problem, the selling price-sensitive and buying price-sensitive
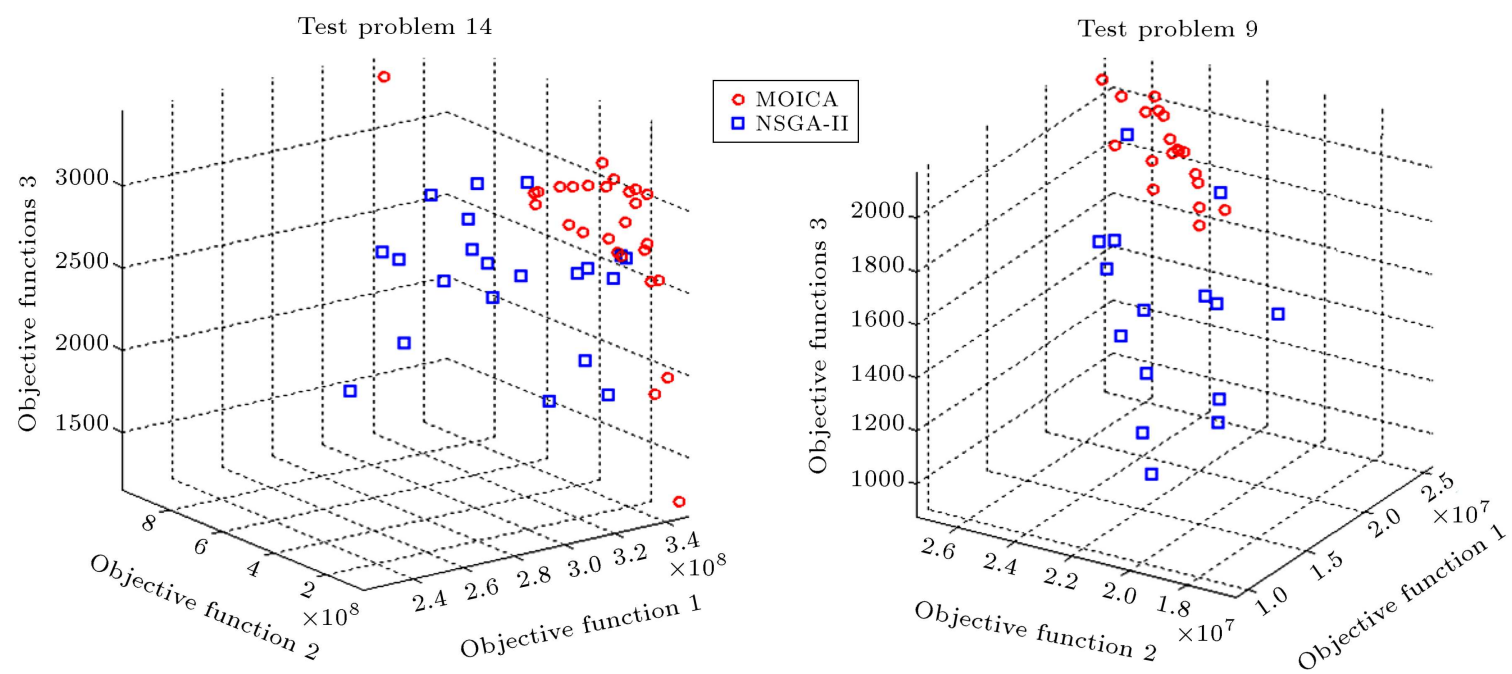

Figure 14. Obtained Pareto-front of algorithms on two test problems 9 and 14 . 
functions were considered in forward and reverse logistics, respectively;

- A Pareto-based multi-objective imperialist competitive algorithm was proposed to solve the MILP model and the results were compared with those of NSGA-II. Comparison of the algorithms indicated the efficiency of the proposed MOICA.

The following future research scopes can be suggested to extend the proposed model:

- In this paper, it is assumed that all parameters are deterministic. Considering the uncertainty of parameters is recommended as an extension to the proposed model.

- Competition among new entrant and existing supply chain can be regarded in future researches.

- Other novel meta-heuristic algorithms can be applied in order to find a better solution approach.

\section{References}

1. Chopra, S. and Meindl, P., Supply Chain Management: Strategy, Planning and Operations, New Jersey: Prentice Hall (2007).

2. Melo, M.T., Nickel, S. and Saldanha-da-Gama F. "Facility location and supply chain management a review", European Journal of Operation Research, 196, pp. 401-412 (2009).

3. Simchi-Levi, D., Kaminsky, P. and Simchi-Levi, E., Designing and Managing the Supply Chain: Concepts, Strategies, and Cases, New York: McGraw-Hill (1999).

4. Altiparmak, F., Gen, M. Lin, L. and Paksoy, T. "A genetic algorithm approach for multi-objective optimization of supply chain networks", Computers \& Industrial Engineering, 51, pp. 197-216 (2006).

5. Zanjirani Farahani, R., Rezapour, S., Drezner, T. and Fallah, S. "Competitive supply chain network design: An overview of classifications, models, solution techniques and applications", Omega, 45, pp. 92-118 (2014).

6. Fattahi, M., Mahootchi, M., Govindan, K. and Moattar Husseini, S.M. "Dynamic supply chain network design with capacity planning and multi-period pricing", Transportation Research Part E, 81, pp. 169-202 (2015).

7. Ahi, P. and Searcy, C. "An analysis of metrics used to measure performance in green and sustainable supply chains", Journal of Cleaner Production, 86, pp. 360377 (2015).

8. Zhang, S. "On a profit maximizing location model", Annual of Operations Research, 103(1), pp. 251-260 (2001).

9. Shen, J.M. "A profit-maximizing supply chain network design model with demand choice flexibility", Operations Research Letters, 34(6), pp. 673-682 (2006).
10. Nagurney, A. and Nagurney, L.S. "Sustainable supply chain network design: a multi-criteria perspective", International Journal of Sustainable Engineering, 3(3), pp. 189-197 (2010).

11. Pishvaee, M.S., Razmi, J. and Torabi, S.A. "Robust possibilistic programming for socially responsible supply chain network design: A new approach", Fuzzy Sets and Systems, 206, pp. 1-20 (2012).

12. Badri, H., Bashiri, M. and Hejazi, T.H. "Integrated strategic and tactical planning in a supply chain network design with a heuristic solution method", Computers \& Operations Research, 40(4), pp. 11431154 (2013).

13. Mota, B., Gomes, M.I., Carvalho, A. and BarbosaPovoa, A.P. "Towards supply chain sustainability: economic, environmental and social design and planning", Journal of Cleaner Production, 105, pp. 14-27 (2014).

14. Ahmadi-Javid, A. and Ghandali, R. "An efficient optimization procedure for designing a capacitated distribution network with price-sensitive demand", Optimization and Engineering, 15(3), pp. 801-817 (2014).

15. Ahmadi-Javid, A. and Hoseinpour, P. "Incorporating location, inventory and price decisions into a supply chain distribution network design problem", Computers \& Operations Research, 56, pp. 110-119 (2015).

16. Govindan, K., Jafarian, A. and Nourbakhsh, V. "Biobjective integrating sustainable order allocation and sustainable supply chain network strategic design with stochastic demand using a novel robust hybrid multiobjective metaheuristic", Computers \& Operations Research, 62, pp. 112-130 (2015b).

17. Aras, N., Aksen, D. and Gonul Tanugur, A. "Locating collection centers for incentive-dependent returns under a pick-up policy with capacitated vehicles", European Journal of Operational Research, 191(3), pp. 1223-1240 (2008).

18. Aras, N. and Aksen, D. "Locating collection centers for distance- and incentive-dependent returns", International Journal of Production Economics, 111(2), pp. 316-333 (2008).

19. Dehghanian, F. and Mansour, S. "Designing sustainable recovery network of end-of-life products using genetic algorithm", Resources, Conservation and Recycling, 53, pp. 559-570 (2009).

20. Tuzkaya, G., Gulsun, B., and Onsel, S. "A methodology for the strategic design of reverse logistics networks and its application in the Turkish white goods industry", International Journal of Production Research, 49(15), pp. 4543-4571 (2011).

21. Neto, J.Q.F., Bloemhof-Ruwaard, J., van Nunen, J. and van Heck, E. "Designing and evaluating sustainable logistics networks", International Journal of Production Economics, 111(2), pp. 195-208 (1998).

22. Shi, J., Zhang, G. and Sha, J. "Optimal production and pricing policy for a closed loop system", Resources, Conservation and Recycling, 55, pp. 639-647 (2011a). 
23. Shi, J., Zhang, G. and Sha, J. "Optimal production planning for a multi-product closed loop system with uncertain demand and return", Computers \& Operation Researches, 38(3), pp. 641-650 (2011b).

24. Chaabane, A., Ramudhin, A. and Paquet, M. "Design of sustainable supply chains under the emission trading scheme", International Journal of Production Economics, 135(1), pp. 37-49 (2012).

25. Pishvaee, M.S. and Razmi, J. "Environmental supply chain network design using multi-objective fuzzy mathematical programming", Applied Mathematical Modelling, 36, pp. 3433-3446 (2012).

26. Keyvanshokooh, E., Fattahi, M., Seyed-Hosseini, S.M. and Tavakkoli-Moghaddam, R. "A dynamic pricing approach for returned products in integrated forward/reverse logistics network design", Applied Mathematical Modelling, 37, pp. 10182-10202 (2013).

27. Devika, K., Jafarian, A. and Nourbakhsh, V. "Designing a sustainable closed-loop supply chain network based on triple bottom line approach: A comparison of metaheuristics hybridization techniques", European Journal of Operational Research, 235, pp. 594-615 (2014).

28. Kaya, O. and Urek, B. "A mixed integer nonlinear programming model and heuristic solutions for location, inventory and pricing decisions in a closed loop supply chain", Computers \& Operations Research, 65, pp. 93103 (2015).

29. Dubey, R., Gunasekaran, A. and Childe S.J. "The design of a responsive sustainable supply chain network under uncertainty", International Journal of Advanced Manufacturing Technology, 80(1), pp. 427-445 (2015).

30. Accorsi, R., Manzini, R., Pini, C. and Penazzi, S. "On the design of closed-loop networks for product life cycle management: Economic, environmental and geography considerations", Journal of Transport Geography, 48, pp. 121-134 (2015).

31. Govindan, K., Soleimani, H. and Kannan, D. "Reverse logistics and closed-loop supply chain: A comprehensive review to explore the future", European Journal of Operational Research, 240, pp. 603-626 (2015a).

32. Elkington, J., Cannibals with Forks: The Triple Bottom Line of 21st Century Business (The Conscientious Commerce Series) (1998).

33. Brundtland, G.H., Our Common Future, Oxford paperbacks (1987).

34. Seuring, S. "A review of modeling approaches for sustainable supply chain management", Decision Support Systems, 54(4), pp. 1513-1520 (2013).

35. Eskandarpour, M., Dejax, P., Miemczyk, J. and Peton, O. "Sustainable supply chain network design: an optimization-oriented review", Omega, 54, pp. 11-32 (2015).

36. Thanh, P.N., Bostel, N. and Peton, O. "A dynamic model for facility location in the design of complex supply chains", International Journal of Production Economic, 113(2), pp. 678-693 (2008).
37. Shen, Z.J. "Integrated supply chain design models: a survey and future research directions", Journal of Industrial and Management Optimization, 3(1), pp. 127 (2007).

38. Salema, M.I.G., Barbosa-Povoa, A.P. and Novais, A.Q. "Simultaneous design and planning of supply chains with reverse flows: a generic modelling framework", European Journal of Operation Research, 203(2), pp. 336-349 (2010).

39. Huang, J., Leng, M. and Parlar, M. "Demand function in decision modeling: a comprehensive survey and research directions", Decision Sciences, 44(3), pp. 557609 (2013).

40. Liu, Z., Qiu, T. and Chen, B. "A study of the LCA based biofuel supply chain multi-objective optimization model with multi-conversion paths in China", Applied Energy, 126, pp. 221-234 (2014).

41. GRI, Global Reporting Initiative - G4 Sustainability Reporting Guidelines, Amsterdam (2013).

42. Deb, K., Pratap, A., Agarwal, S. and Meyarivan, T. "A fast and elitist multi-objective genetic algorithm: NSGA-II", IEEE Transactions on Evolutionary Computation, 6, pp. 182-197 (2002).

43. Atashpaz-Gargari E. and Lucas C. "Imperialist competitive algorithm: An algorithm for optimization inspired by imperialist competition", IEEE Congress on Evolutionary Computation (2007).

44. Enayatifar, R., Yousefi, M., Abdullah, A.H. and Darus, A.N. "MOICA: A novel multi-objective approach based on imperialist competitive algorithm", Applied Mathematics and Computation, 219, pp. 88298841 (2013).

45. Srinivas, N. and Deb, K. "Multi-objective function optimization using non-dominated sorting genetic algorithms", Evolutionary Computation, 2(3), pp. 221248 (1995).

46. Zitzler, E. and Thiele L. "Multi-objective optimization using evolutionary algorithms a comparative case study", Fifth International Conference on Parallel Problem Solving from Nature (PPSN-V), Berlin, Germany, pp. 292-301 (1998).

47. Zitzler, E. "Evolutionary Algorithms for multiobjective optimization: method and applications", Ph.D. Thesis, Swaziland Federal Institute of Technology Zorikh, Switzerland (1999).

48. Mousavi, M., Hajipour, V., Niaki, S.T.A. and Aalikar, N. "Optimizing multi-item multi-period inventory control system with discounted cash flow and inflation approaches: Two calibrated meta-heuristic algorithms", Applied Mathematical Modelling, 37, pp. 2241-2256 (2013).

49. Hajipour, V., Rahmati, S.H.A., Pasandideh, S.H.R. and Niaki S.T.A. "A multi-objective harmony search algorithm to optimize multi-server location-allocation problem in congested systems", Computers \& Industrial Engineering, 72, pp. 187-197 (2014). 
50. Fattahi, P., Hajipour, V. and Nobari, A. "A biobjective continuous review inventory control model: Pareto-based metaheuristic algorithms", Applied Soft Computing, 32, pp. 211-223 (2015).

51. MATLAB Version 7.10.0.499 (R2010a). The MathWorks, Inc. Protected by U.S. and International Patents (2010).

\section{Biographies}

Arash Nobari is currently working for $\mathrm{PhD}$ degree in Industrial Engineering at Bu-Ali Sina University, Hamedan, Iran. He obtained BS and MS degrees in Industrial Engineering from Khaje Nasir Toosi University of Technology (KNTU), Tehran, Iran, in 2010 and 2012, respectively. His research interests include logistics planning, supply chain management, game theory approach, mathematical modeling, and metaheuristic algorithms.

Amirsaman Kheirkhah received his $\mathrm{PhD}$ degree in Industrial Engineering from Iran University of Science and Technology, Tehran, Iran, in 2004, and is currently Associate Professor of Industrial Engineering at Bu-Ali Sina University, Hamedan, Iran. His research interests include production planning, logistics planning, and crew scheduling. Moreover, he is more specifically active in mathematical modelling and solving techniques, including exact procedures, and meta-heuristic algorithms. 